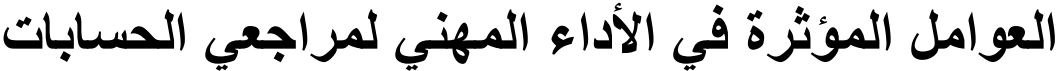 الخارجيين في قطاع غزة من دولة لاعنة فلسطين
}

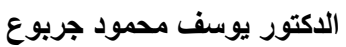

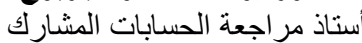 \\ كلية التجارة - قسم المحاسبة الجنابة

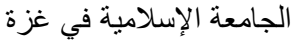 \\ "ASCA" وزميل المجمع العربي للمحاسبين القانونيين فأل
}

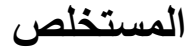

إن الثقة في رأي المر اجع الخارجي للقو ائم المالية المنشورة تتوقف على على أدائه المهني واستقلاله

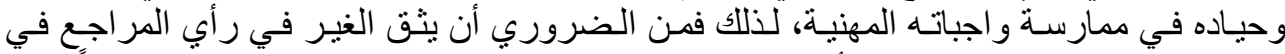

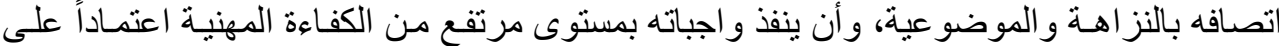

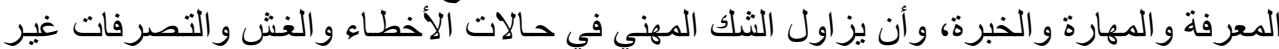

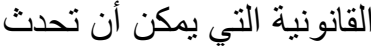

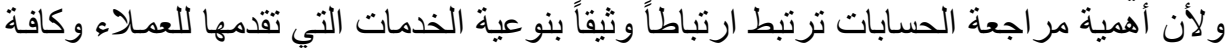

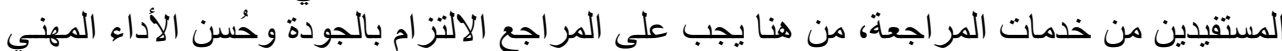
المطلوب منه أثناء تنفيذه المهام الموكولة إلبه من البها

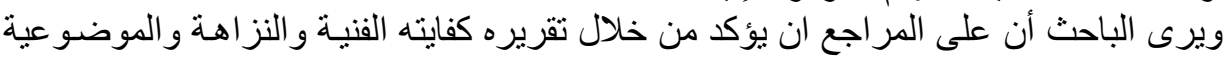

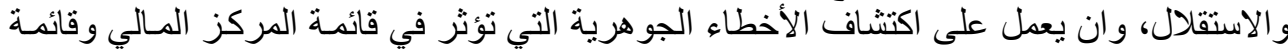

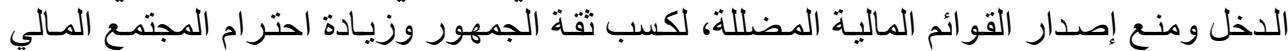

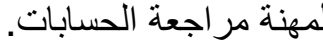

\section{مقدمة}

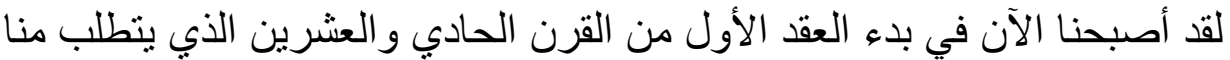

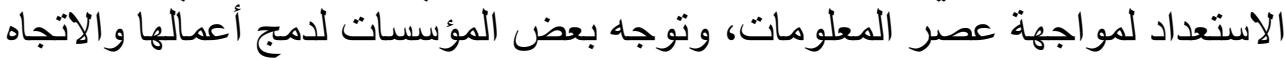
نحو تحويل بعض مؤسسات القطاع العام إلى القطاع الخاص، مما سيؤدي إلى زيـادة

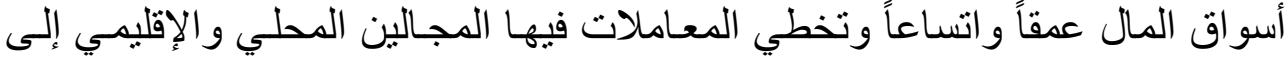

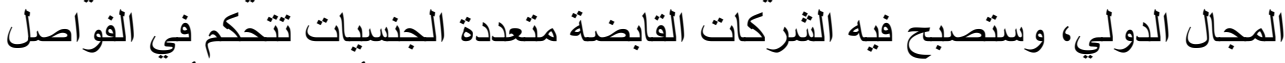
الاستر اتيجية للاقتصاد العالمي، وسوف يترتب على على ما سبق أن تزداد الأهمية النسبية

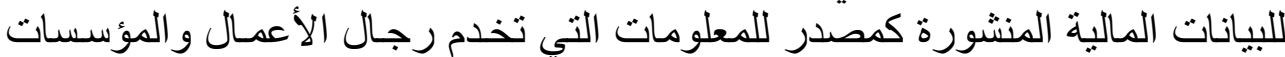

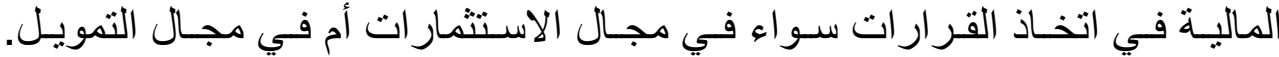

(Jennings, 1986-1987,104-115) ولكي تفي البيانات المالية المنشورة باحتياجات مستخدميها في المجالات المشار إليها آنفاً، لابد من تو افر شرطين أساسيين هما: 
ا ـ أن تتسم المعلومات التي توفرها تلك البيانات بقدر معقول من المصداقية ليكون

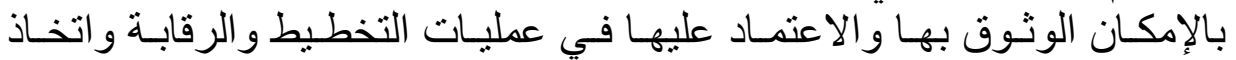

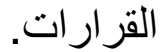

r. أن تكون تللك المعلومات قابلة للمقارنة، وذلك كي تحوز المؤشرات المشتقة منها

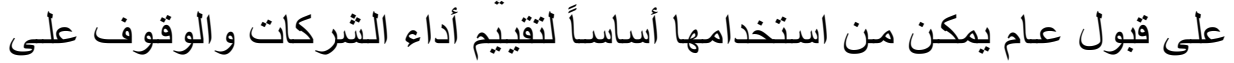

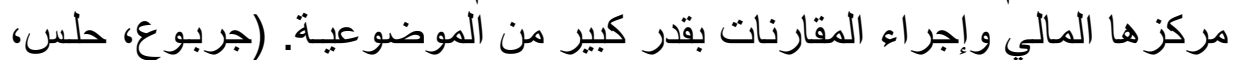

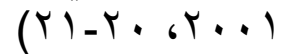
ولكن لا توجد عملية مر اجعة تستطيع أن تعطي تأكيدات كاملة بأن القوائم المالية

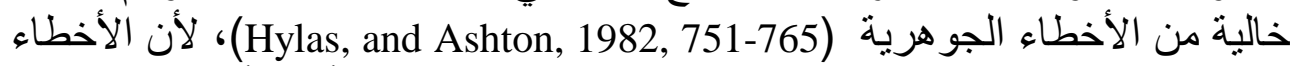

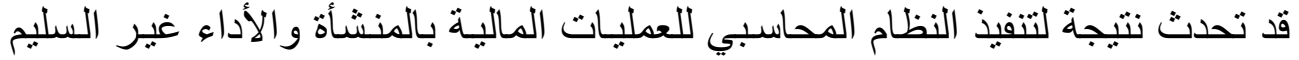

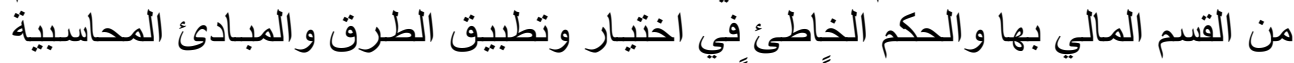
المتعارف علبهاً و المقبولة قبو لاًاً عاماً.

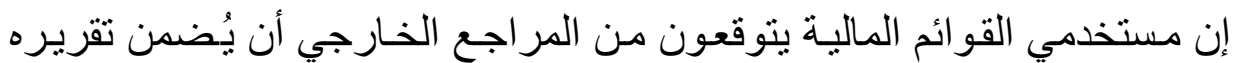

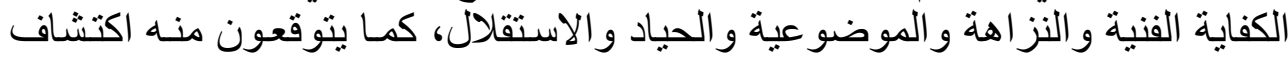

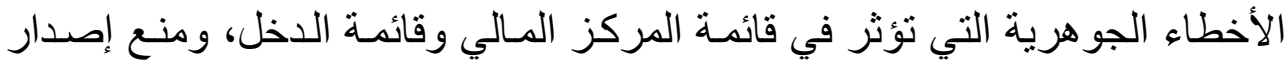
القو ائم الماليبة المضللة. (Albrecht, and (Boyntan, and Kell, 1996, 53-54) Willingham, 1993,102-124)

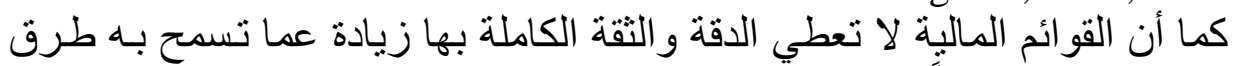

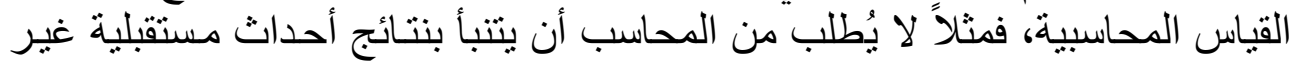

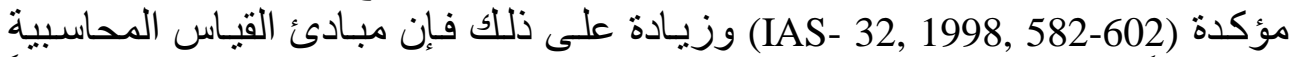

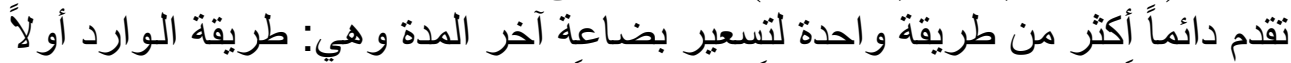

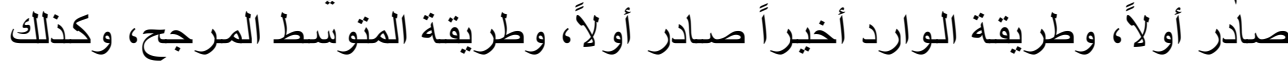

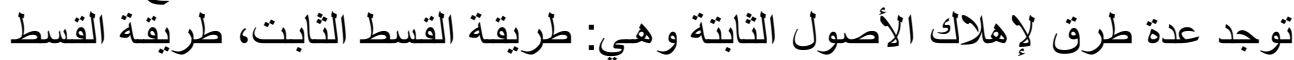

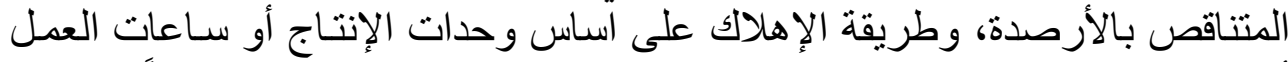

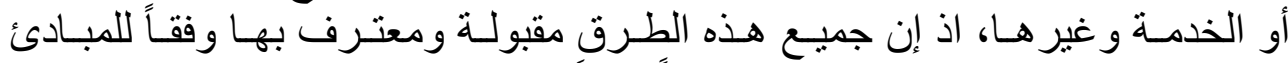

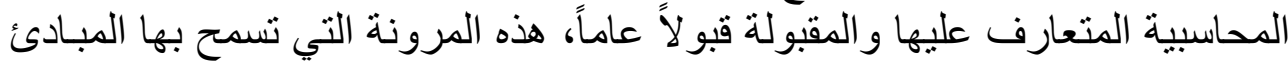

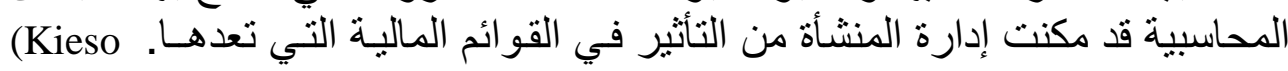
and Weygandt, 1998,404-410).

(Mosich, and Larsen, 1986, 604-610). أنظر على سبيل المثال: - ان

(Arens, and Loebbecke, 1988, 241-250).

(Meigs, and Meigs, 1981, 462-475).

(Meigs, and Meigs, 1990, 388-394).

(Smith, et. al., 1986, 341-358).

(Fess, and Warren, 1984, 270-273).

(Larsen, 1989,314-318).

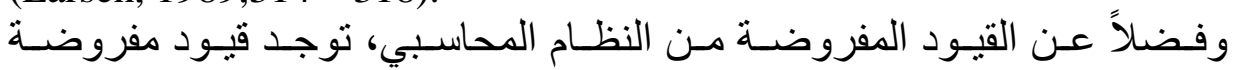

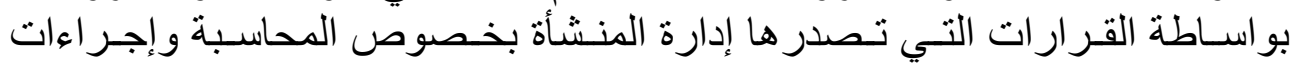


الرقابة و التي تستخدمها في معالجة العمليات المالية، إن إدارة المنشاة تصدر قرار اتها

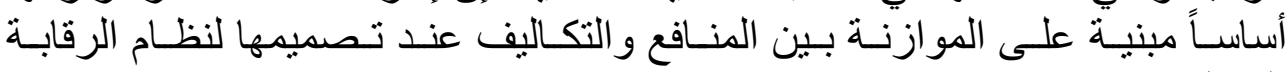
الداخليـة.

(Cohen and Kida, 1989, 263-275).

(Georgiades, 2001, 148-153).

(Jancura, and Lilly, 1977, 69-74).

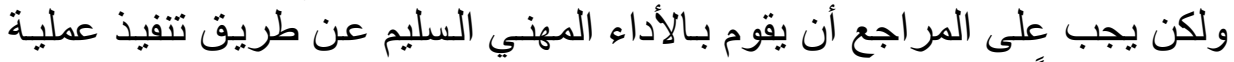

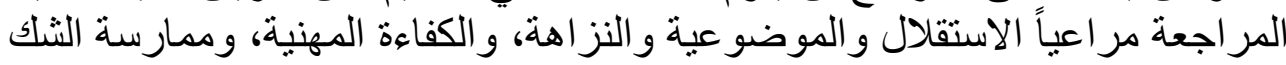

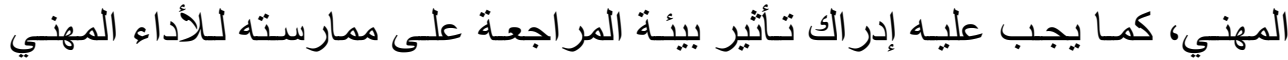

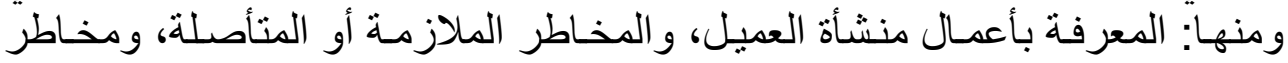

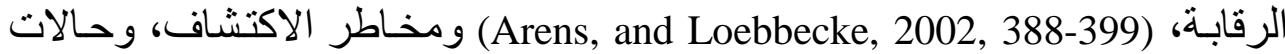

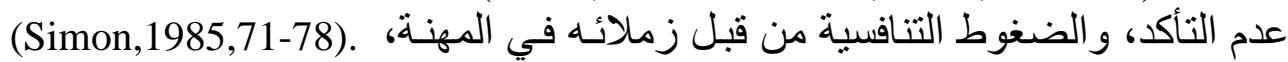

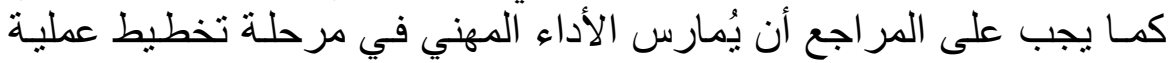

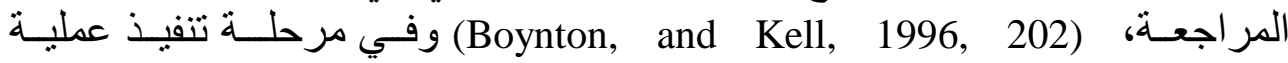
المراجعة، (AICPA, 1984, GAAP) وفي مرحلــة إعداد تقريـر المراجعـة.

(Grinaker, 1980, 63 -69)

\section{مشكلة البحث}

تكمن مشكلة هذا البحث في عدم التزام المر اجع الخـارجي بـالأداء المهني السليم

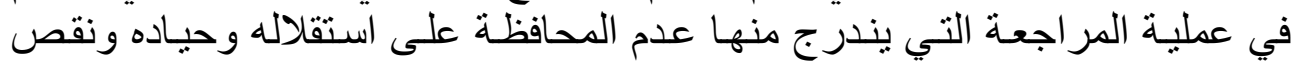

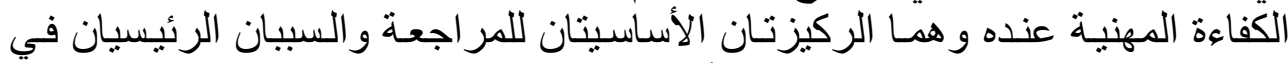

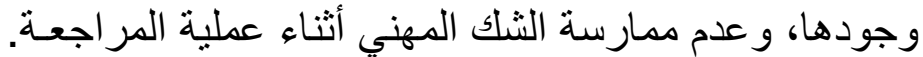

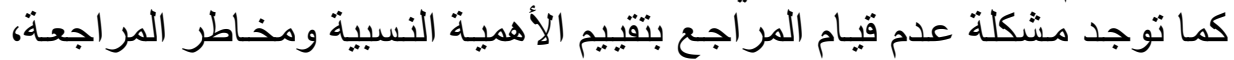

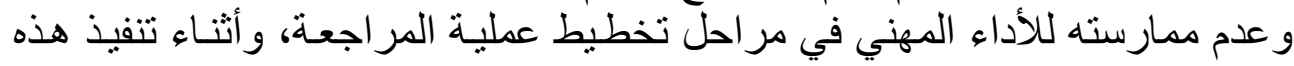
العملية، وفي مرحلـة إعداد التقرير النهائي لعملية المر اجعة.

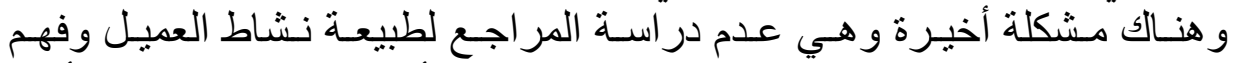

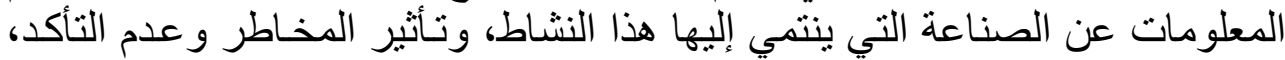
وتأثير الضغوط التنافسية على المراجع.

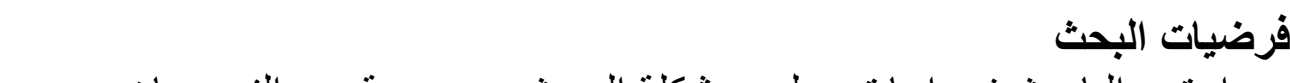
اعتمد الباحث في اجابته على مشكلة البحث بمجموعة من الفرضيات حسب

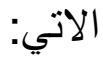

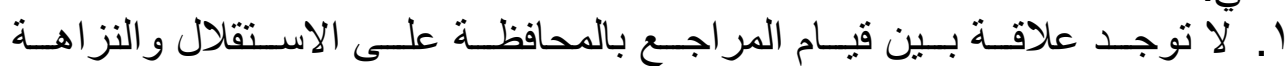

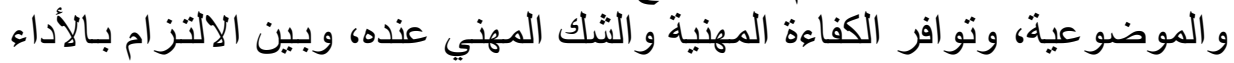


r. لا توجد علاقة بين تقييم الأهمية النسبية ومخاطر المراجعة، وبين الالتز ام بالأداء

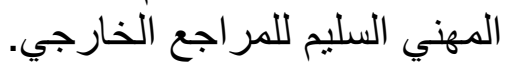

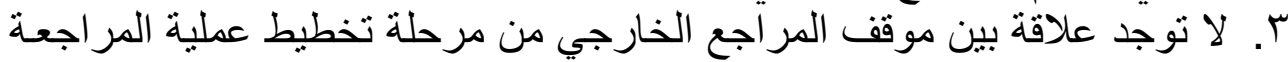

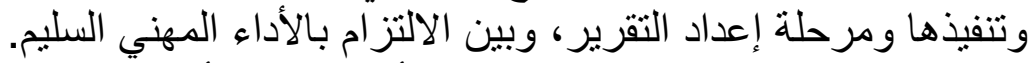

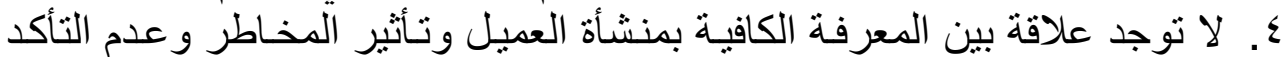
وتأثير الضغوط التنافسية على المراجع الخارجي، وبين الالتزام بالأداء المهني.

هدف البحث

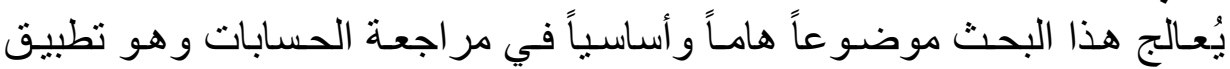

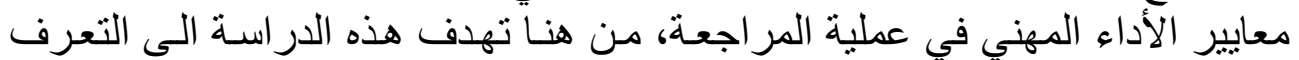

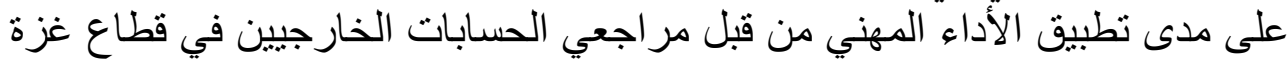
من دولة فلسطين. كما يهدف هذا البحث إلى التعرف على المى الأسباب التي تؤدي إلى عدم ممارسـة

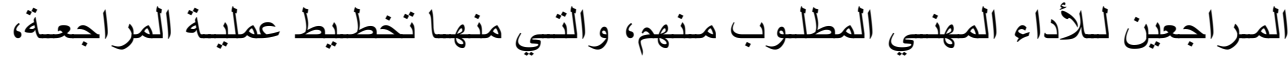

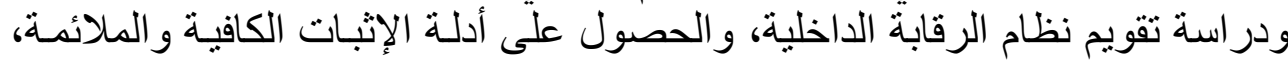

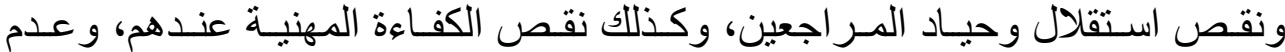

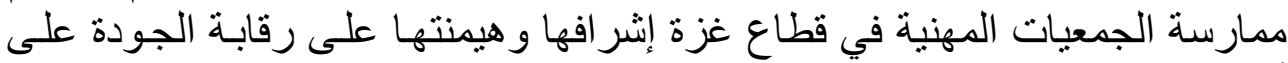
أعمال مكاتب المر اجعـة.

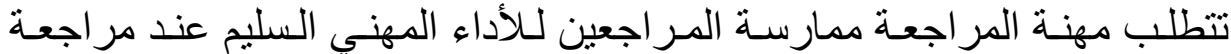
أهمبة البحث

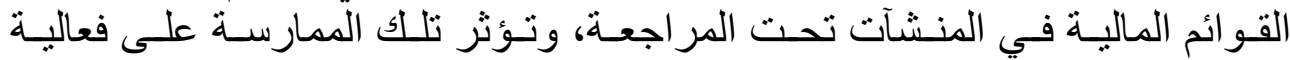
المر اجعة، وثقة مستخدمي القوائم المالية في تقارير المر المعين.

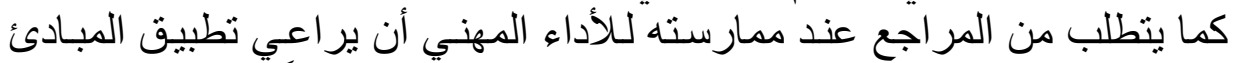

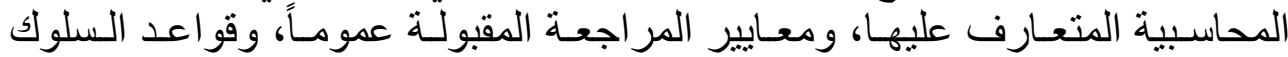

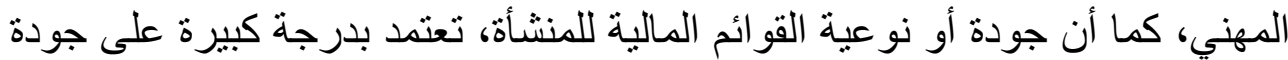

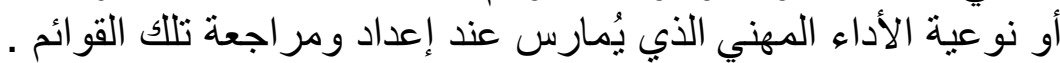

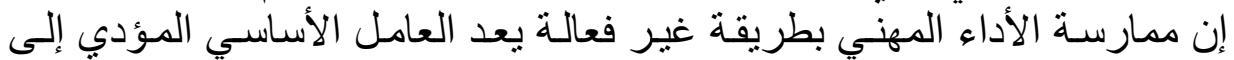

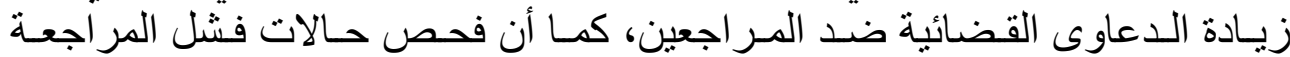

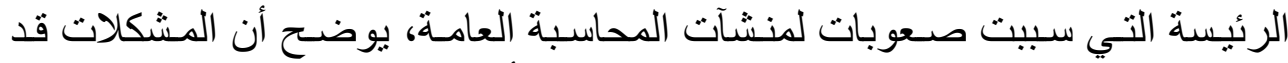

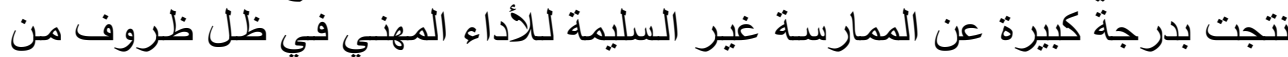
الاجتهاد والتوتر، و لا يمكن إخفاء حقيقة أن أداء المر اجعين في تلأك الحالات كان أقل فئل

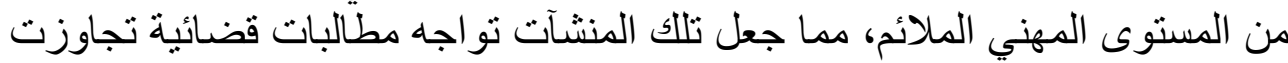
V لبيون دو لار أمريكي نتيجة لأخطاء التدقيق وقصور في أنظمـة الرقابـة الداخليـة لايهـا. 


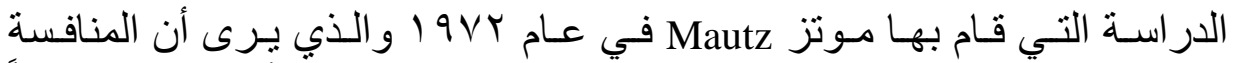

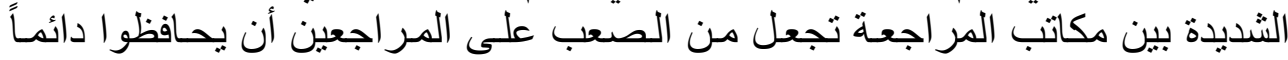

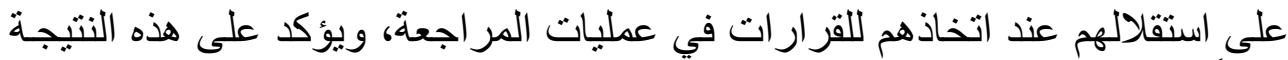

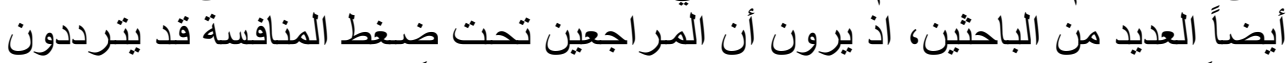

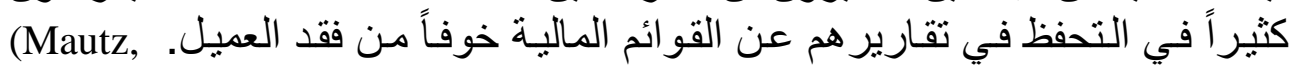
1972,91)

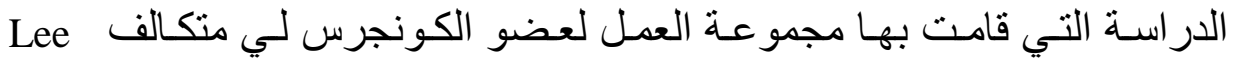
Metcalf

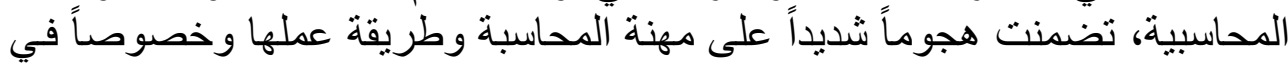
مجال الاستقلال (Metaclf Staff Report, 1976) و المنافسة بين مكاتب المحاسبة و عمل معايير للمحاسبة و المر اجعة.

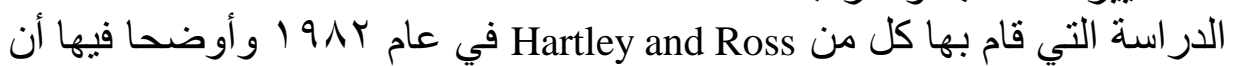

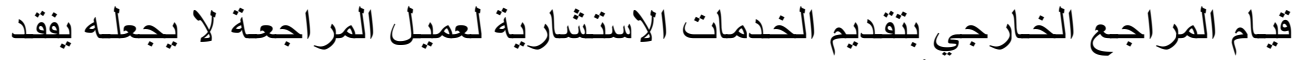

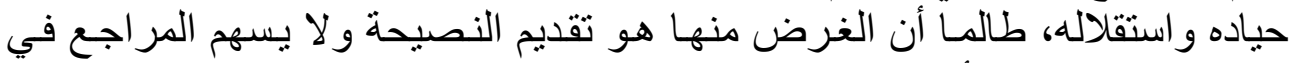

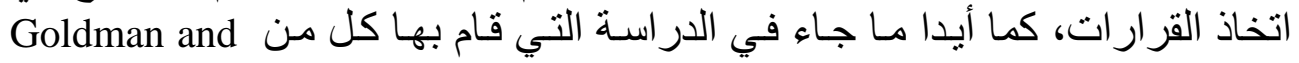
. (Hartley and Ross, 1982, 42-52) Barlev

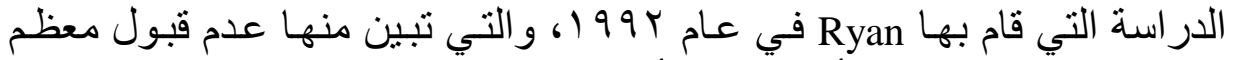

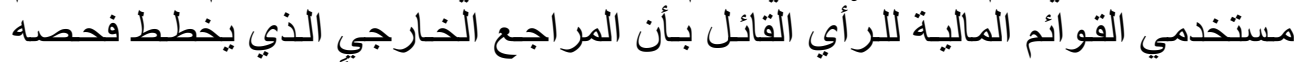

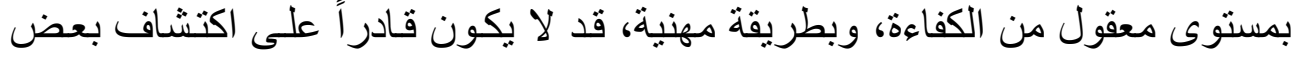
حالات الغش الهامة. (Ryan Commission, 1992, 74)

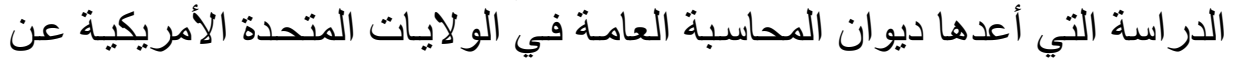

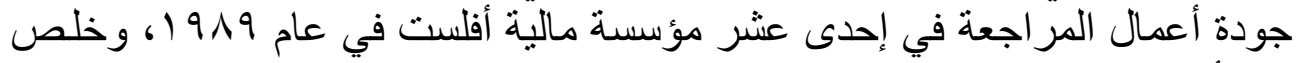

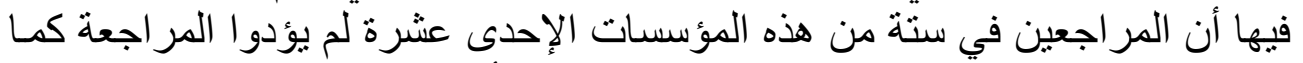

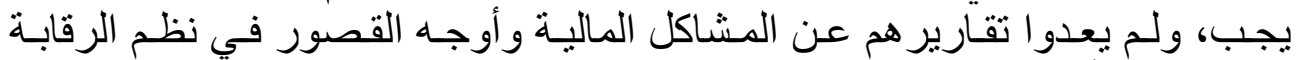

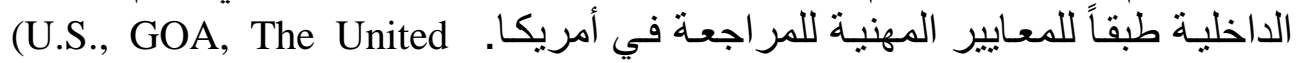
States General Accounting Office, 1989).

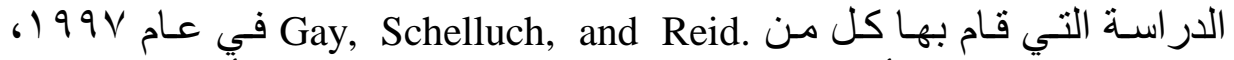

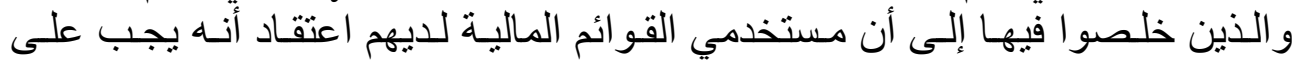

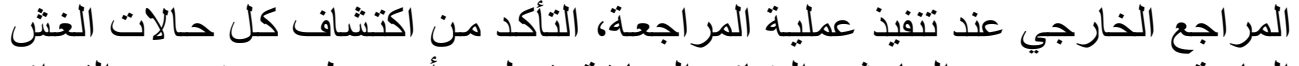

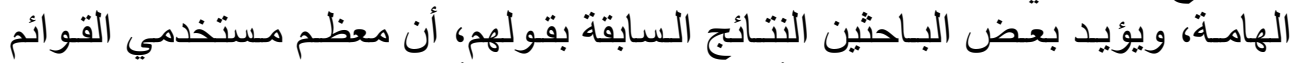

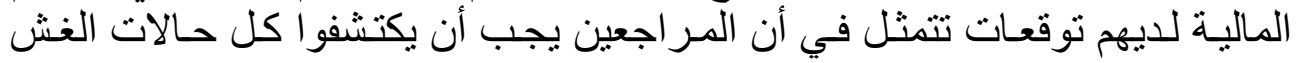

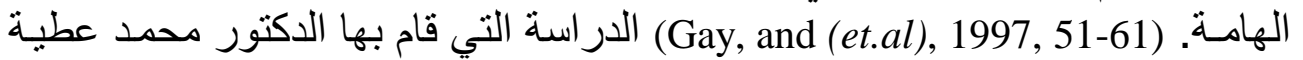

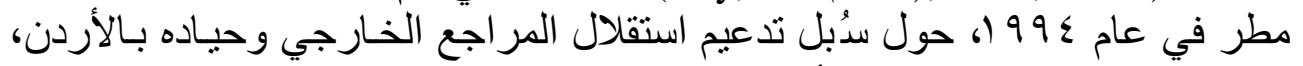

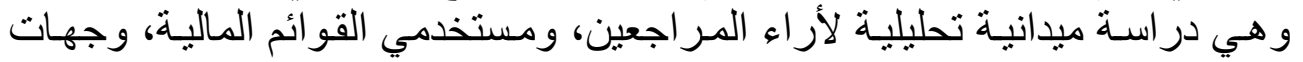

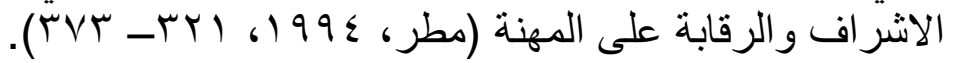

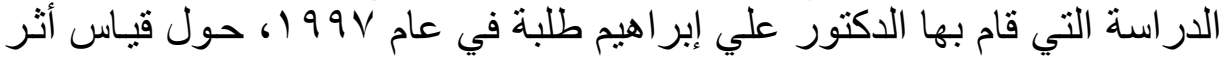

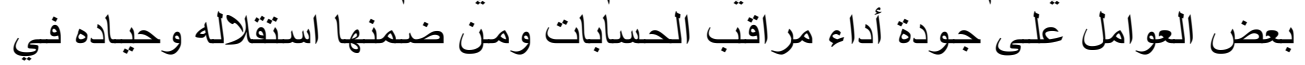


ممارسة مهنته، وهي در اسة ميدانية على مكاتب المر اجعة في سلطنة عُمـان. (طلبـة، (rV-1T، $699 \mathrm{~V}$

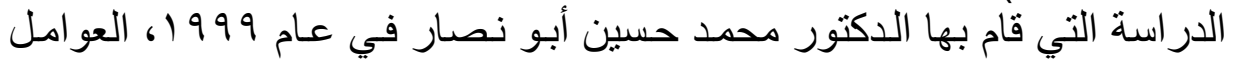

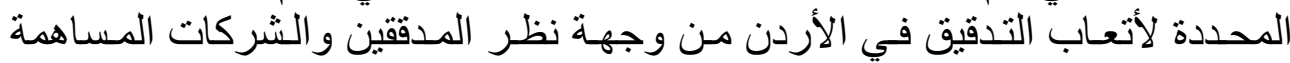

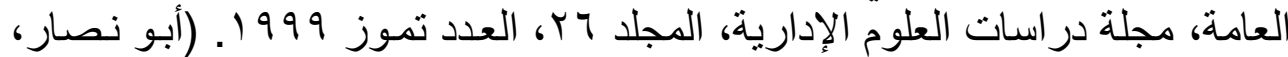

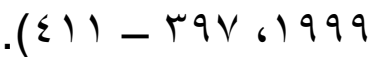

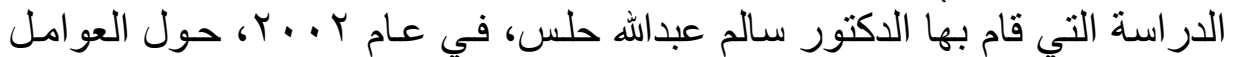

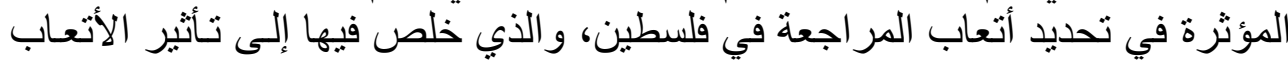

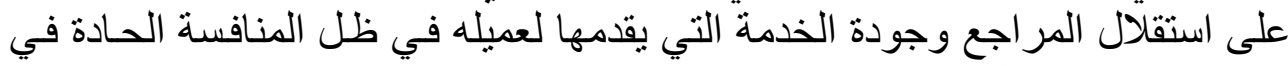

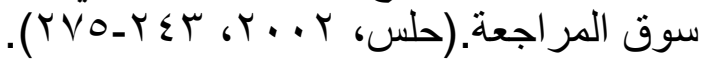

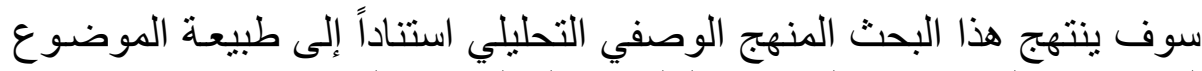

\section{منهجية البحث}

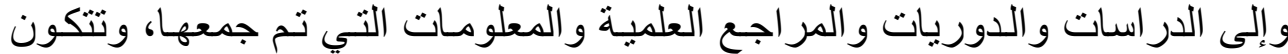
هذه المنهجية من الآتي :

أولاًَ الاراسة النظرية وتثثتمل على المباحث الاتيـة:

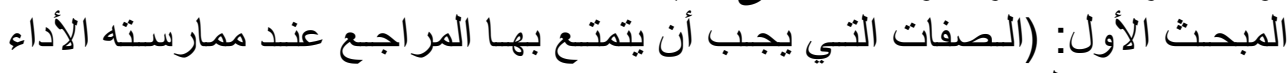

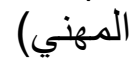

ا ـ. المحافظة على الاستقلال الكل و الموضو عية و النز اهـة.

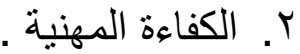

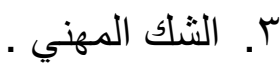

المبحث الثاني: (المو اقف التي تتطلب ممارسة المر اجع للأداء المهني)

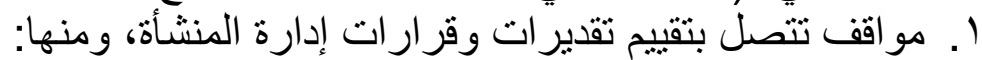

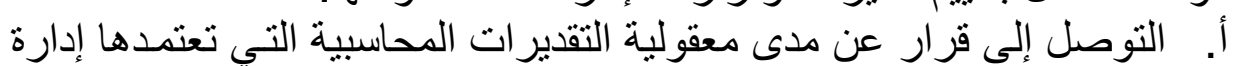

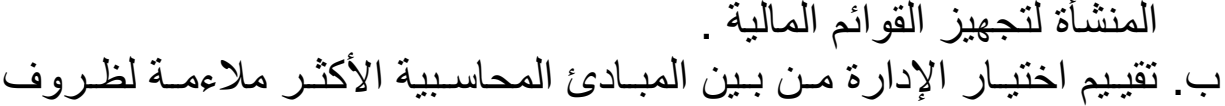
المنشأة . Y. . مو اقف ذات علاقة بعملية المر اجعة، ومنها:

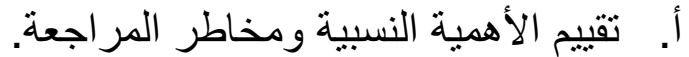

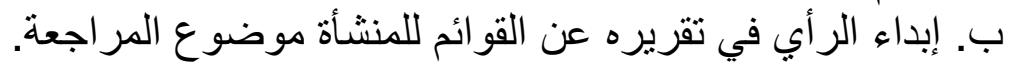
المبحث الثالث: (موقف المراجع الخارجي من مر احل عملية المر اجعة)

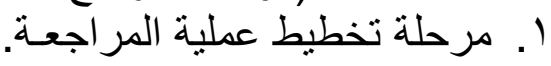

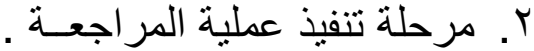

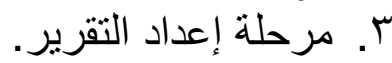

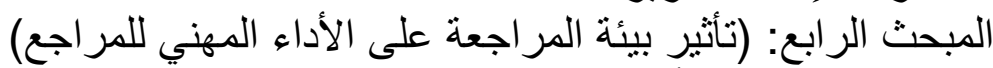

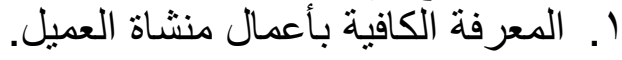


r. r. تأثير المخاطر و عدم التأكد على ممارسة المر اجع للأداء المهني.

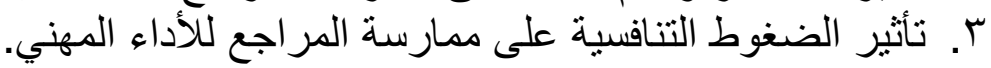

\section{الصفات التي يجب أن يتمتع بها المراجع عند ممارسته الأداء المهني}

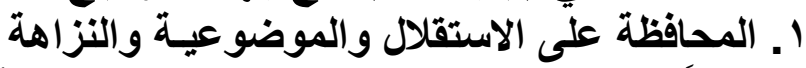

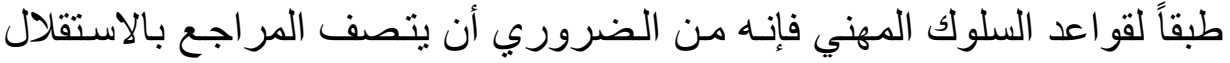

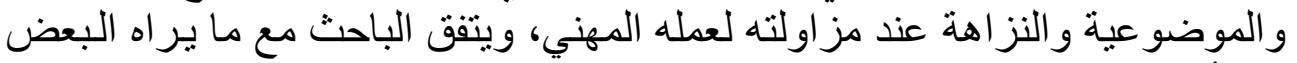

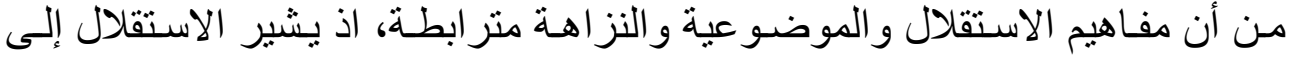

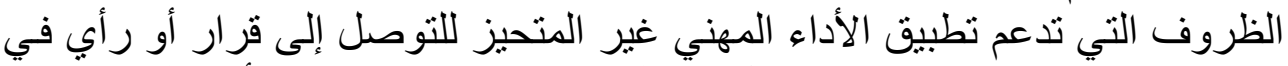

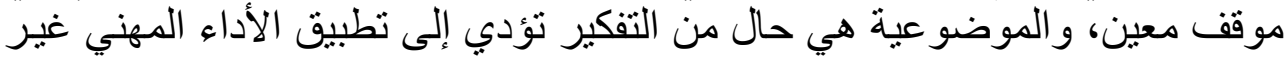

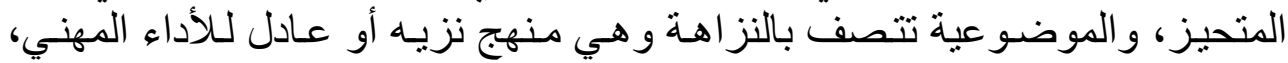

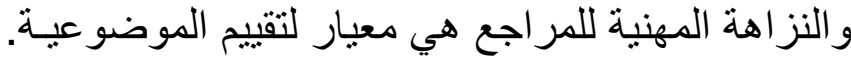

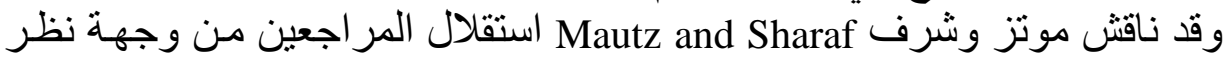

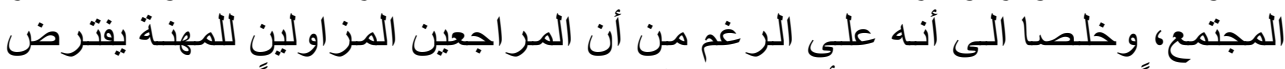

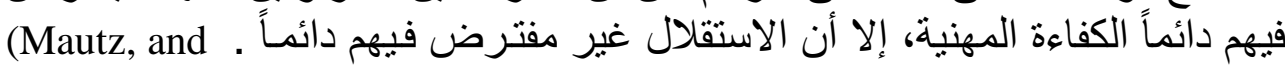

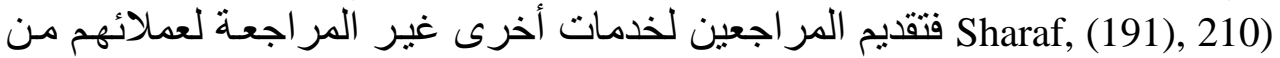

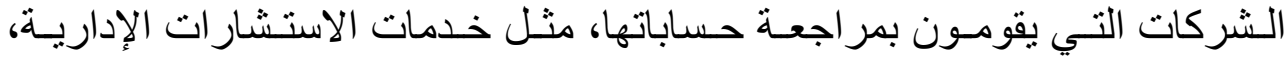

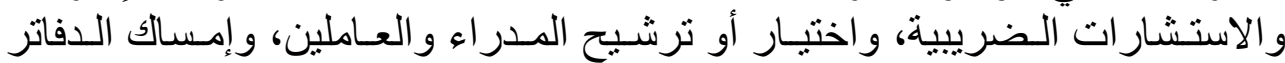

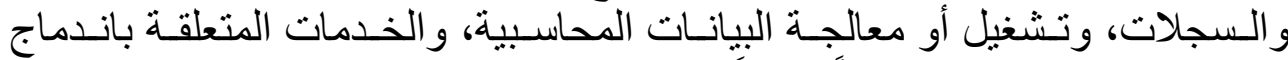

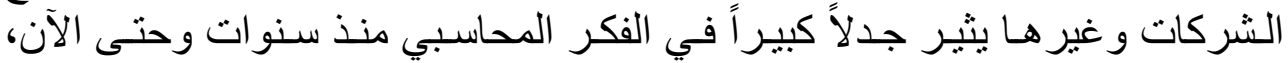

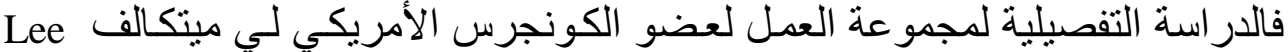
Metaclf

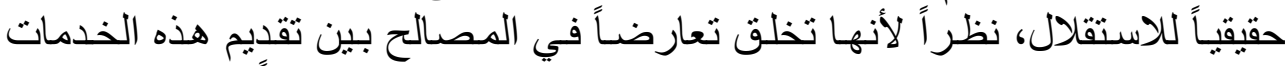

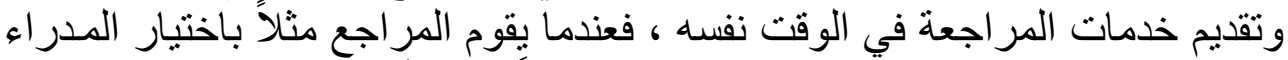

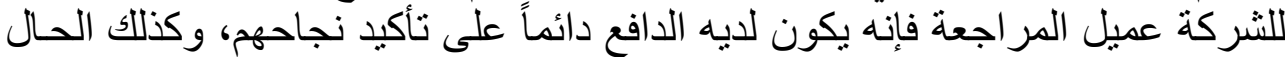

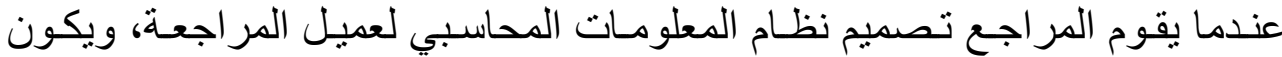

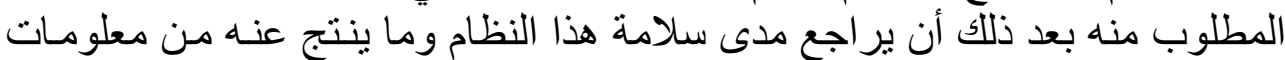
محاسبية وإمكانية الاعتماد عليها.

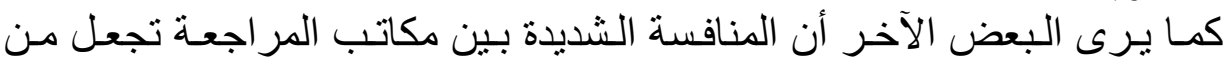

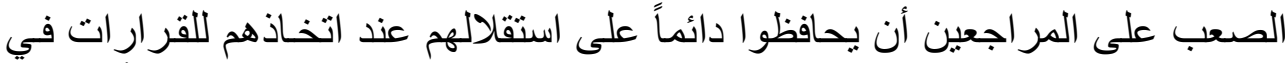

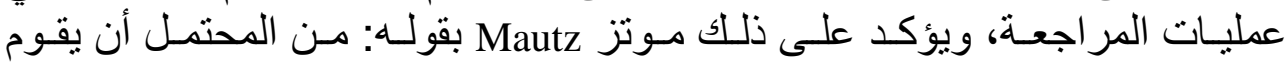

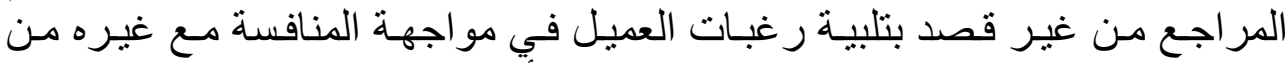

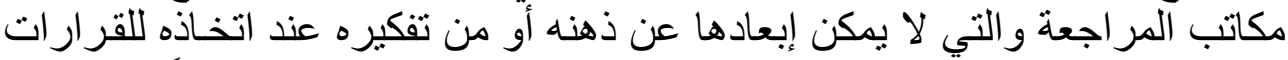

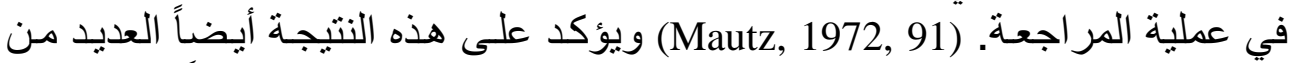

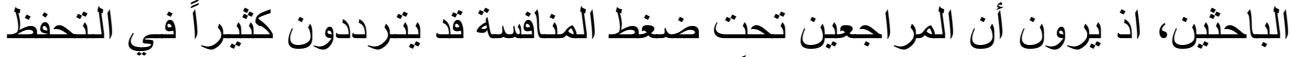

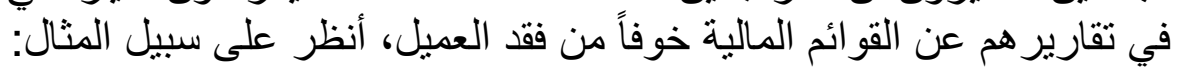


(Firth, 1980, 451-466).

(Shockley, 1981,785 - 800).

(Nichol, and Smith, 1983, 534 - 544).

(Citron, and Toffler, 1990).

(Waller, 1990, 56).

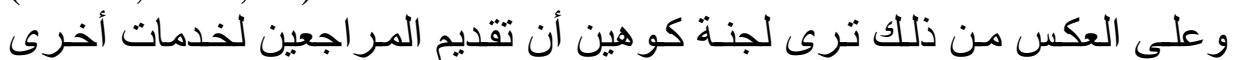

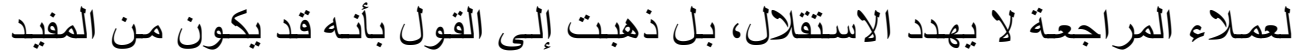

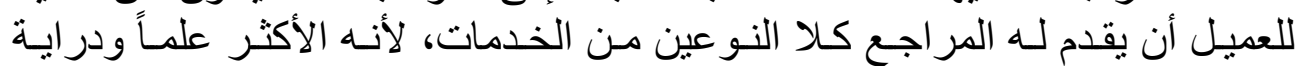

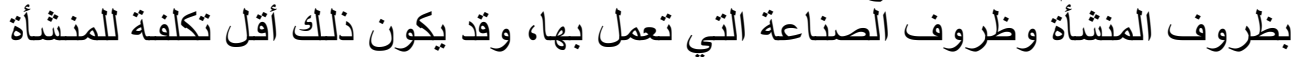

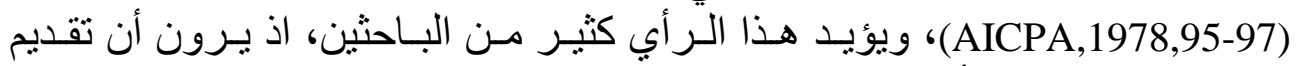

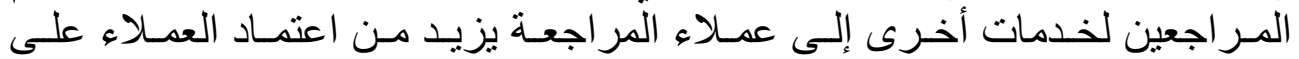
المر اجعين ومن ثم يقلل من اعتماد المر اجعين، أنظر على سبيل المثنال:

(Goldman, and Barlev, 1974, 707-718)

(Nichols, and Price,1976, 335-346).

(Simmic, 1984, 679-702).

(Antle, 1987, 1-20).

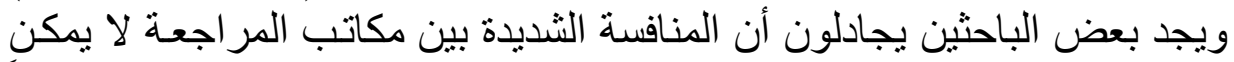

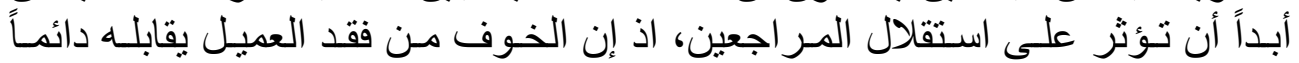

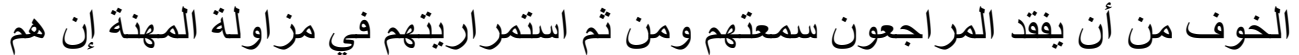

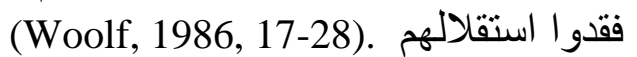

ومن وجهات النظر السابقة المتعارضة يتبين بوضوح أن استقلال المر اجعين مـا

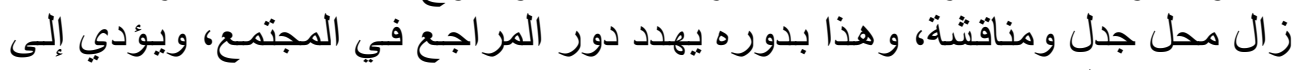

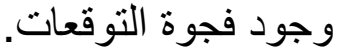

\section{r ب. الكفاعة المهنية}

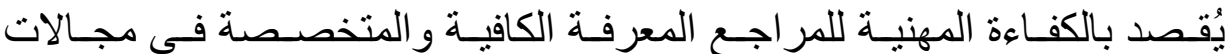

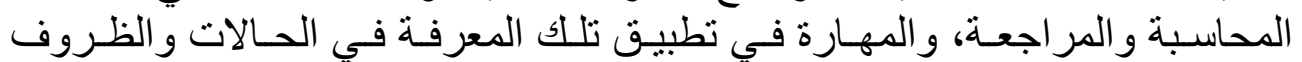

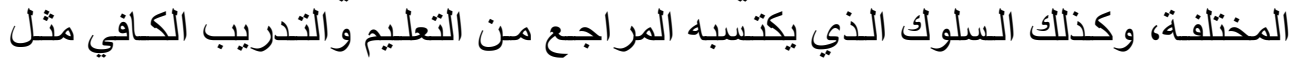
الاستقلال. (Jarvis, 1983, London, Groom helm).

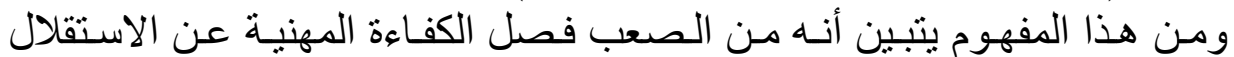
كدعامتين أساسيتين للمر اجعة و السببين الرئيسين في وجودها. الردا. و وعلى الرغم من تأكيد

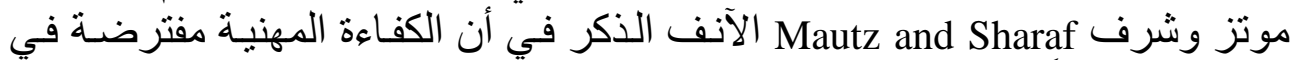

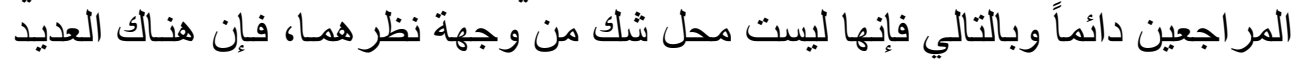

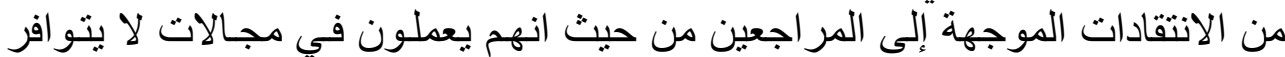

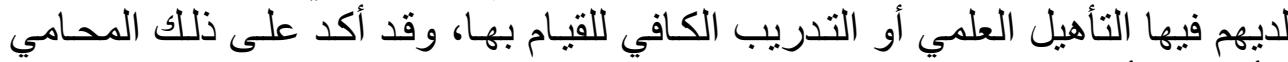

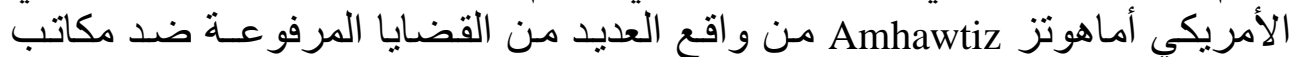

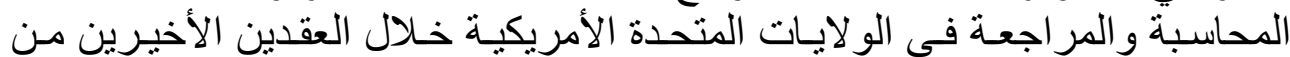
القرن العثرين الماضي. 


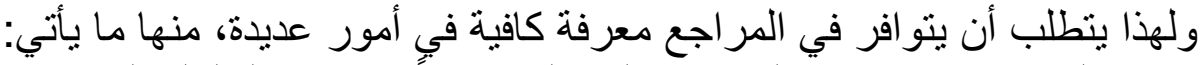

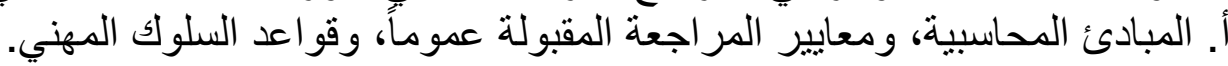

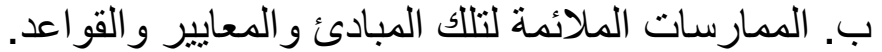
ت. أثر التطور ات في الحاسبات الإلكترونية على مزاولة الكاتلة المر اجع لعمله المهني.

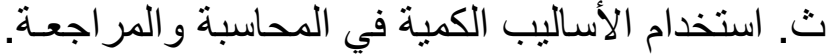

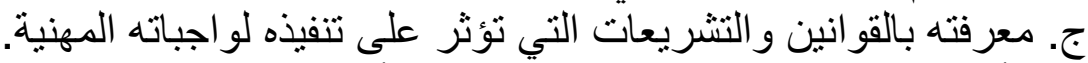

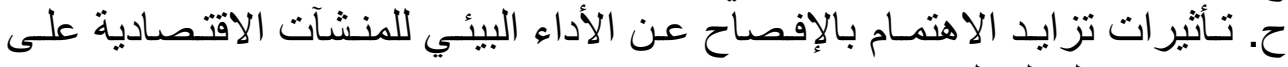

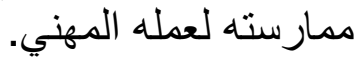
خ. تأثيرات النمو في احتياجات مستخدمي القوائم المالية على ممارسة المراجع لعمله

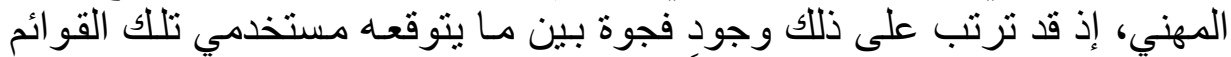

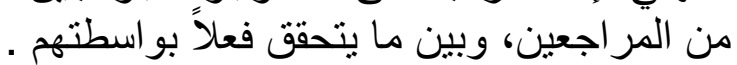

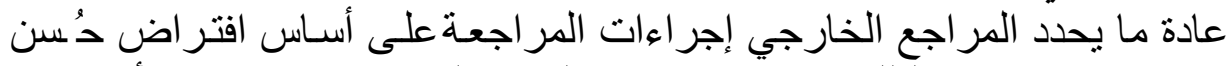

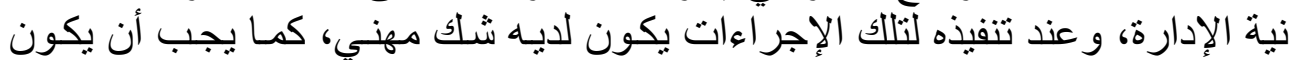

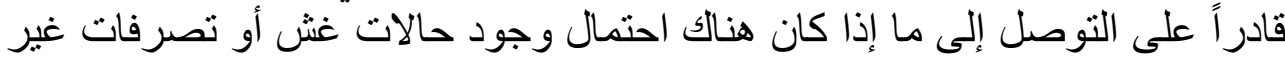
قانونية وأخطاء، (Matsumura, and Trucker, 1992) أنظر على على سبيل الآن المثال: (Glover, and Aono, 1995, 3 - 4).

(Madision, and Ross, 1990, 41).

(AICPA, 1988, Circular No. 53, No. 54).

(Castello, 1991, 17).

(Read, (et.al), 1996, 28-34).

(Robson, 1988, 356 - 360).

وأن يحصل على تأكيد معقول عمـا إذا كانت القو ائم الماليـة خالية من أيسة

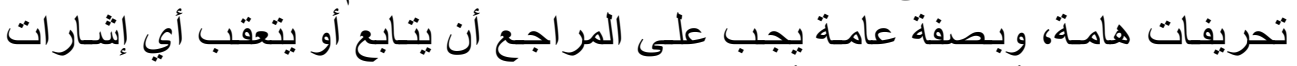

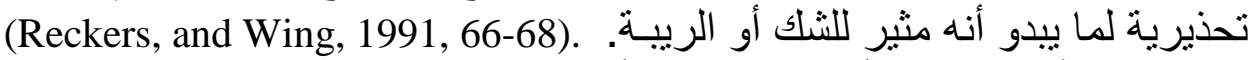

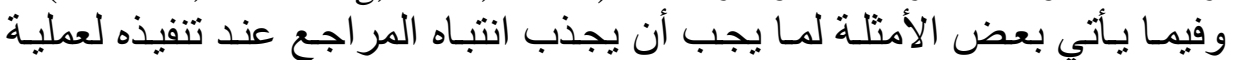

أ. أن هناك قيود أو حدود على نطاق الفحص قد فرضت عليه من إدارة المنشأة.

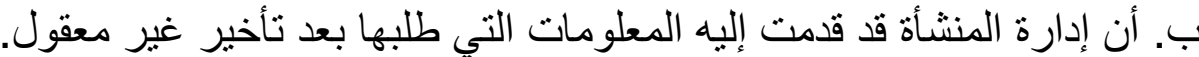

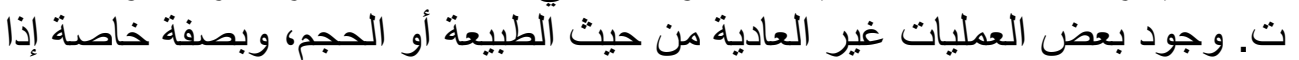
كانت في أواخر الفترة الماليـة.

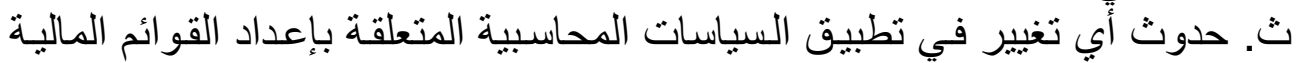

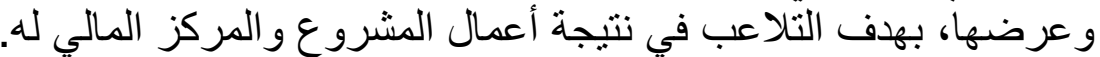

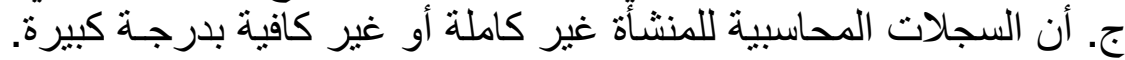

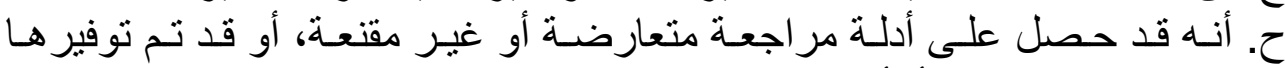
بوساطة إدارة المنشأة أو العاملين فيها. 


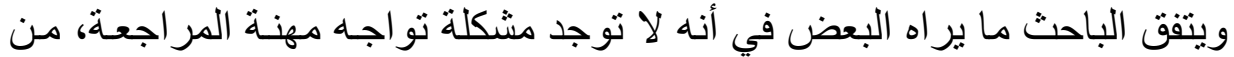

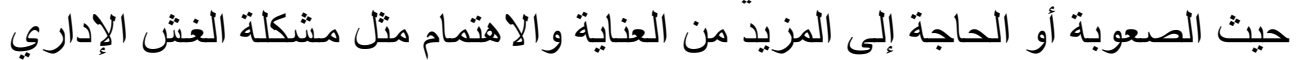

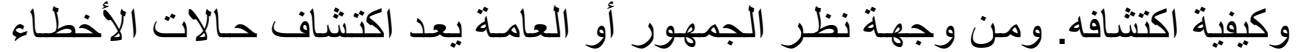

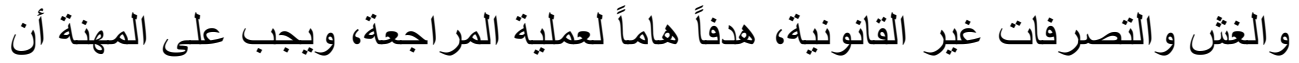

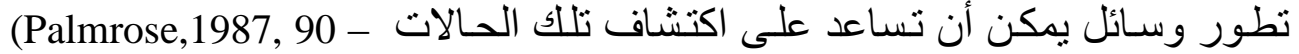
103).

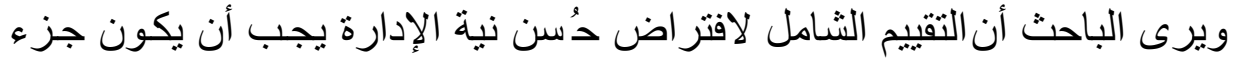

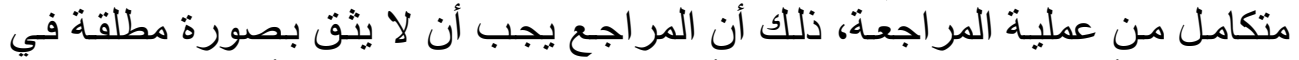

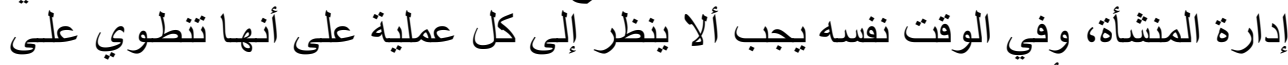

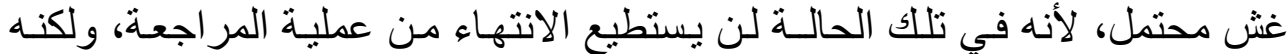

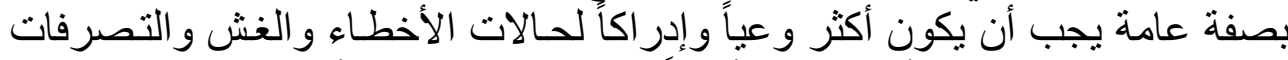

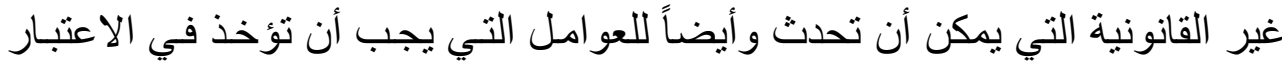
عند تقييم احتمالات حدوث تللك الحالات.

\section{المواقف التي تتطلب ممارسة المراجع للأداء المهني}

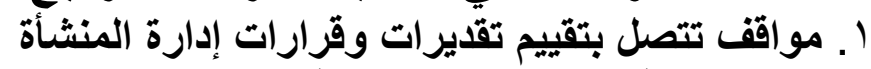
أ. مدى معقولية التقديرات المحاسبية

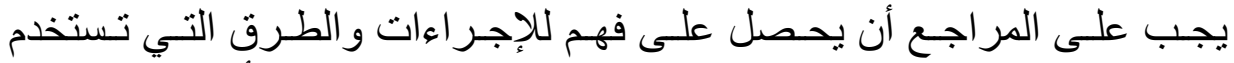

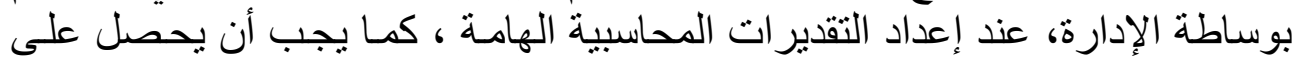

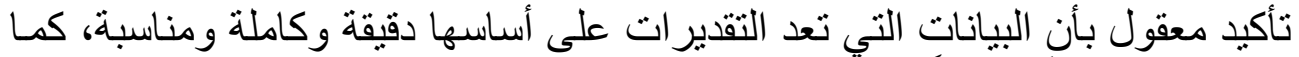

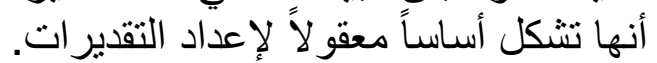

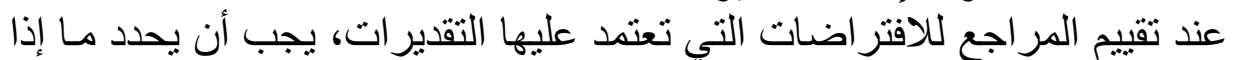

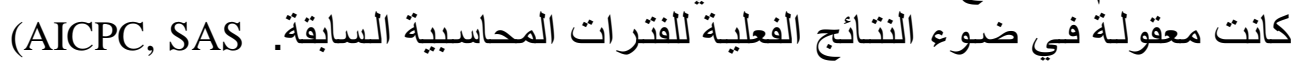
(Wallace, 1993, 125-176). No. 57, 1988).

ب. تقييم اختيار الإدارة للمبادئ المحاسبية الأكثر ملاءمة لظروف المنشأة

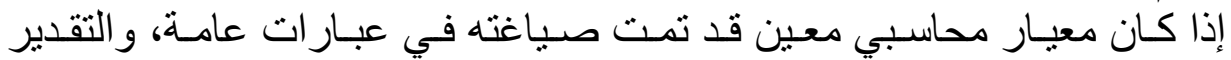

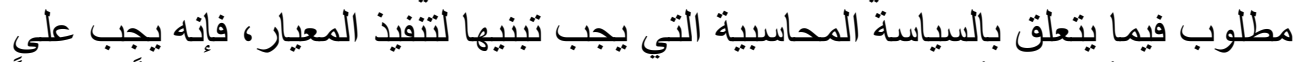

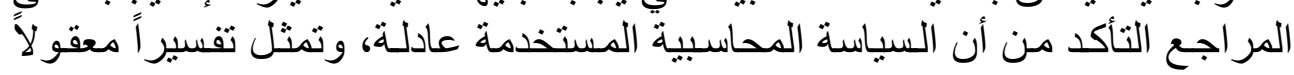
لروح المعيار.

r. بواقف ذات علاقة بعملية المراجعة، ومنها

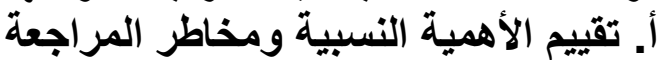

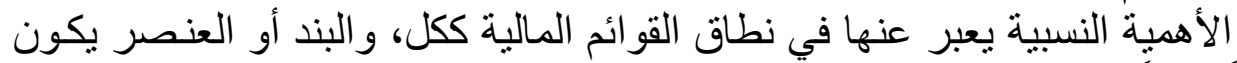
هاماً نسبياً إذا كان من المنوقع، أُن يترتب على على عدم أخذه في الاعتبار أو سوء تلقديره 
(Chidgey, and Mitchell, 1995, 203). تأثثير على قرار ات مستخدمي القوائم المالية.

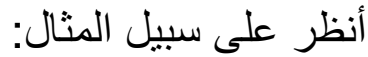

(Chewning, (et.al), 1981, 482-501).

(Krogstad, (et.al), 1984,54-74).

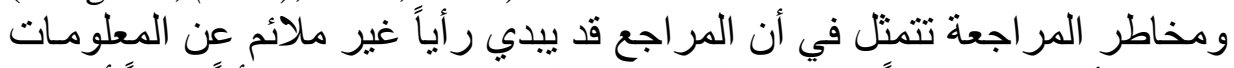

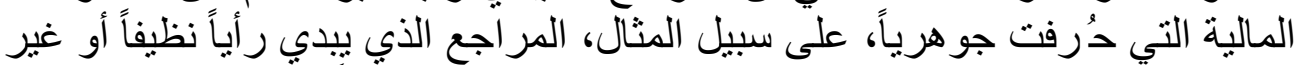

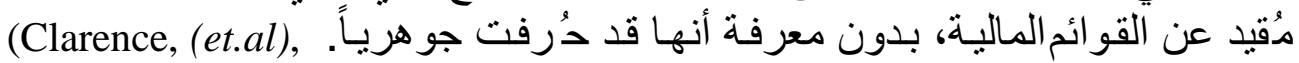
1991).

(William, (et.al), 2000,).

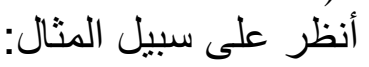
وتركز وجهة النظر المهنية في المر اجعة على تقييم مخاطر المر اجعة في مرحلة

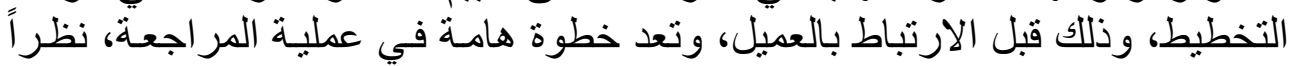

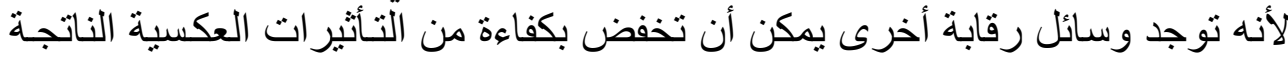

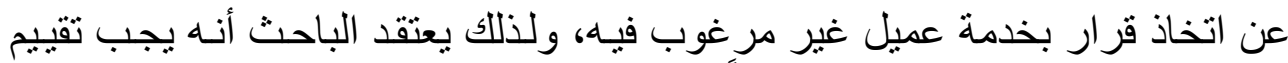

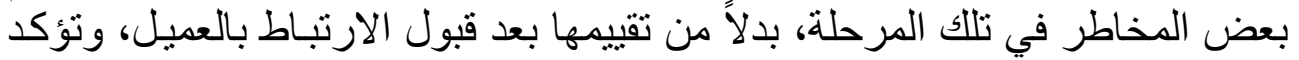

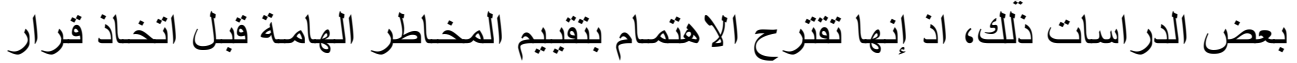

(Skeratt, and Woodhead, 1992,122-125).

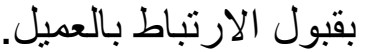

(Huss, and Jacobs, 1991, 20-25).

بـ إبداء الرأي في تقريز المراجع عن القوائم المالية

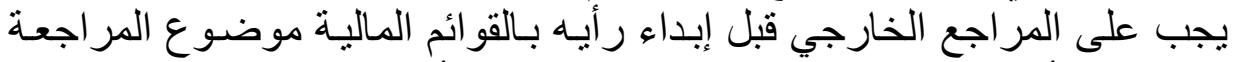

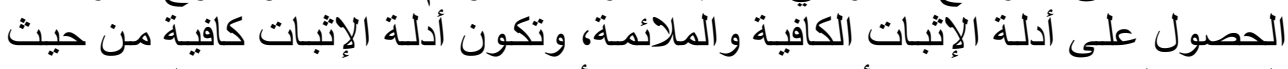

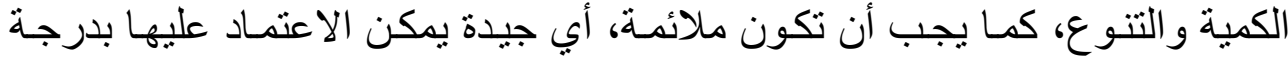

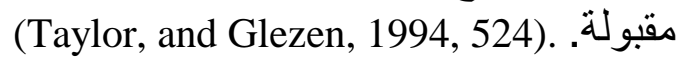

\section{موقف المراجع الخارجي من مراحل عملية المراجعة}

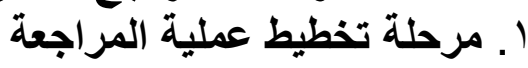

يعد تخطبط عملية المر اجعة من المبادئ الأساسية التي تحكم المسؤولئه الميات المهنيـة

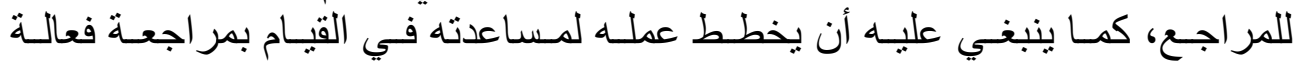

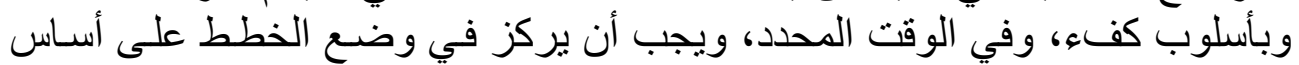

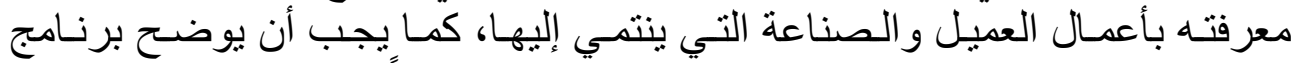

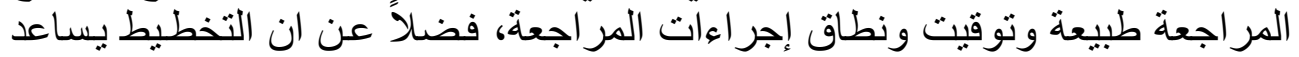

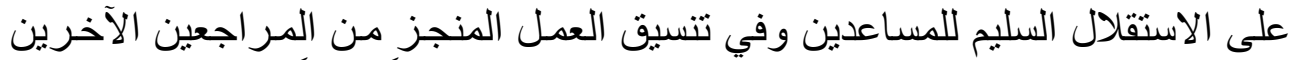

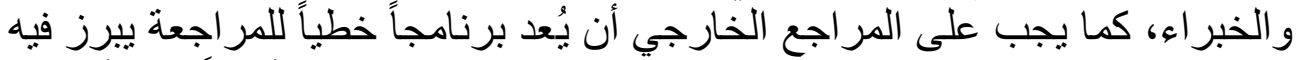

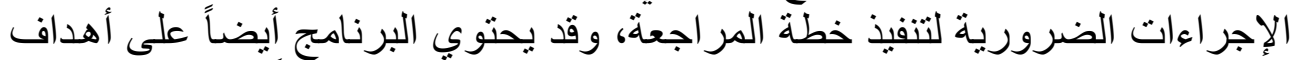

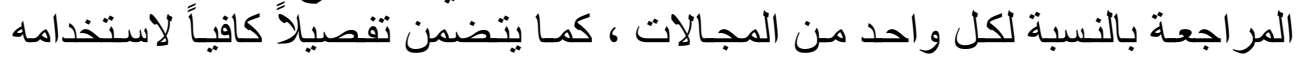


كمجمو عة من التعليمات للمساعدين المشاركين في عملية المر اجعة ووسيلة للرقابـة على تنفيذ العمل بشكل سليم، أنظر على سبيل المنالئ المنال

(Boynton, and Kell, 1996, 41).

(Bailey, and (et.al) 1974, 3572-574).

(Gipple, and Metacif, 1974, 38 - 46).

(Stetter, 1982, 116 - 123).

Y. مرحلة تثفيذ عملية المراجعة

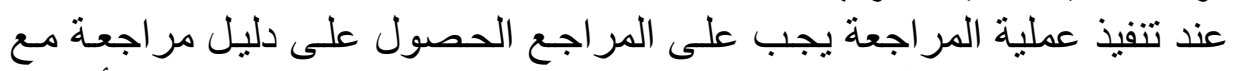

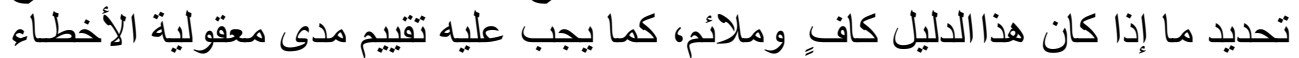

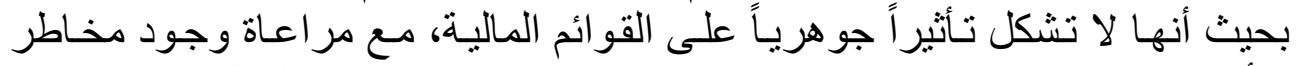

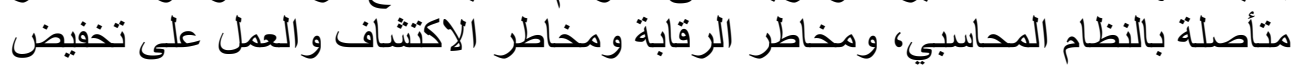
تللك المخاطر إلى أدنى حد ممكن.

\section{r. مرحلة إعداد التقرير}

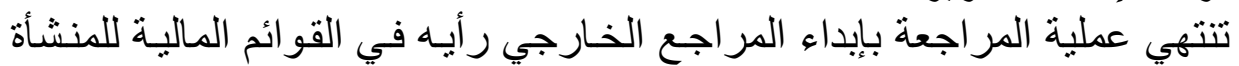

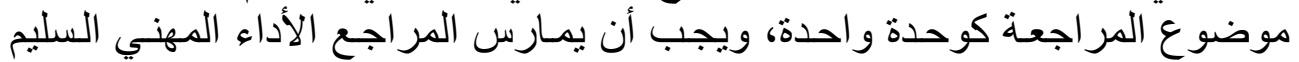
عند إبداء ذلك الرأي، ورأي المراجع قد أئ وأخذ أحد الأشكال التالية:

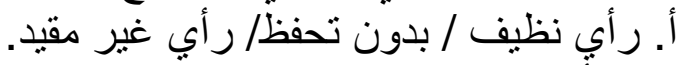
ب. ب. رأي متحفظ/ مقيد. ت. ت. رأي سلبي (معاكس). ث. الامتناع عن إبداء الري (معاكي) أبي.

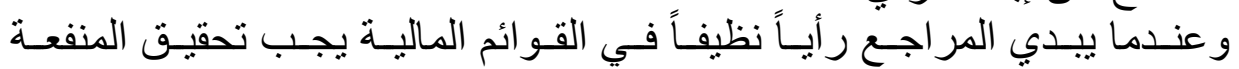

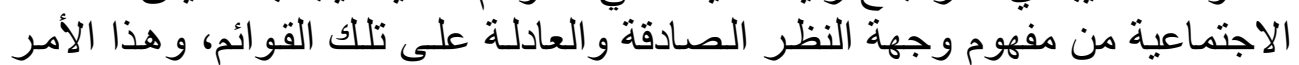

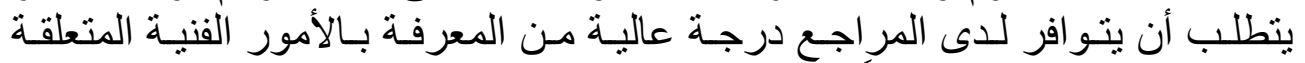

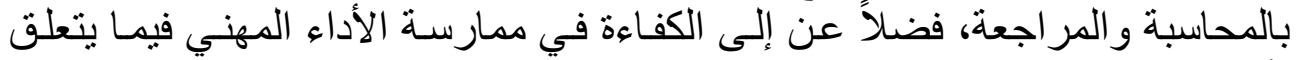

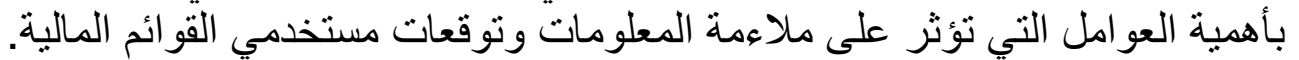

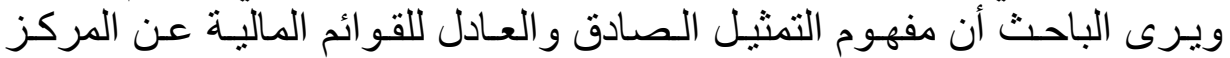

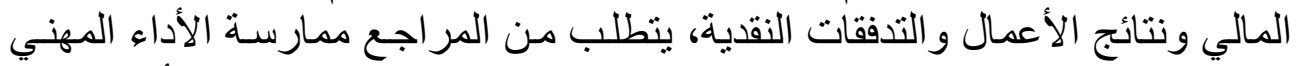

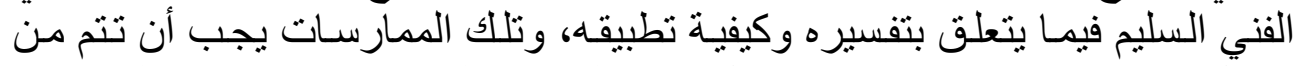

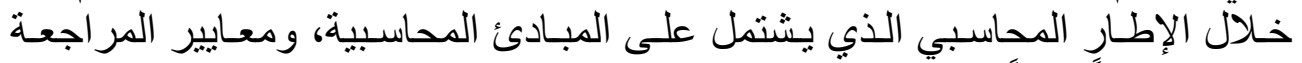
المقبولة قبو لاً عاماً، وقو العد السلوك الكي المهني.(Parker, and Nobes, 1991, 352) (Higson, and Blake, 1993, 104 - 105).

(Waller, 1980, 53).

(Renshall, 1976, 105-106). 


\section{تأثير بيئة المراجعة على الأداء المهني للمراجع}

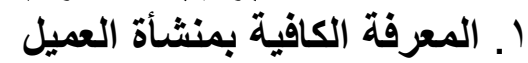

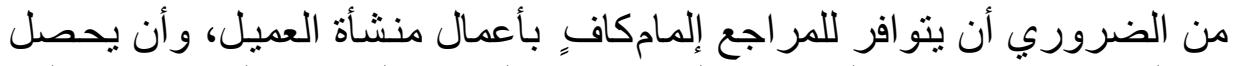

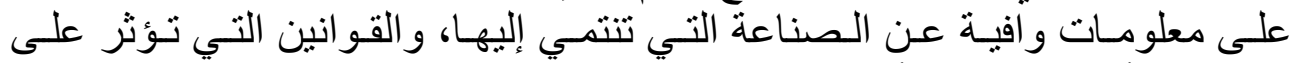

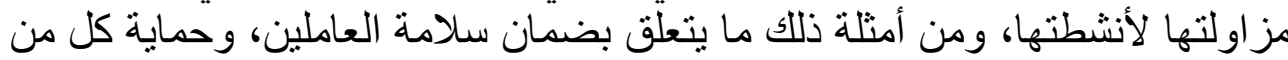

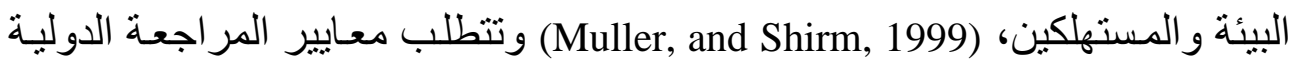

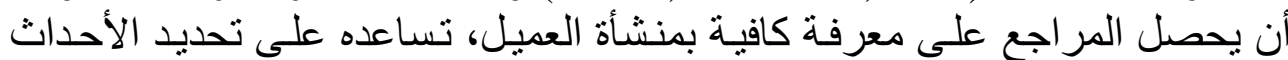

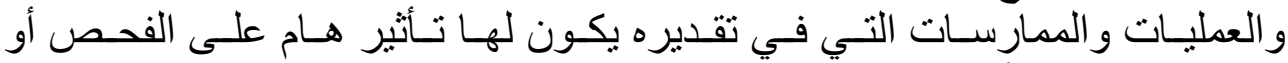

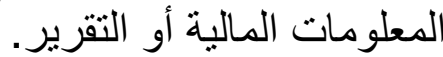

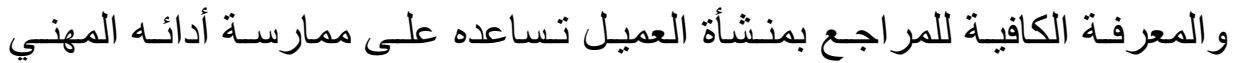

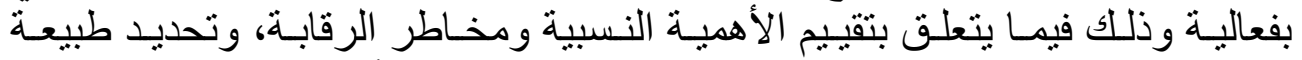

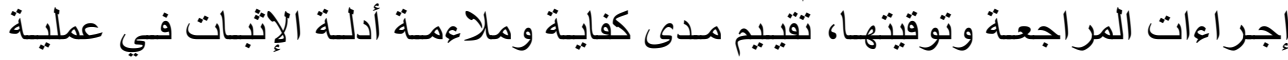

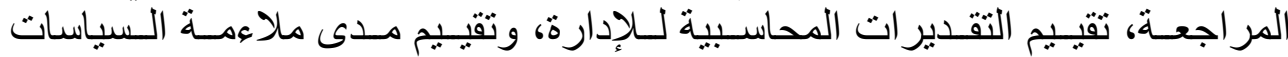
المحاسبية المطبقة ومدى كفاية الإفصاح في القوائم المالية.

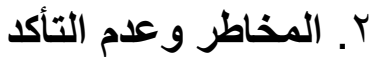

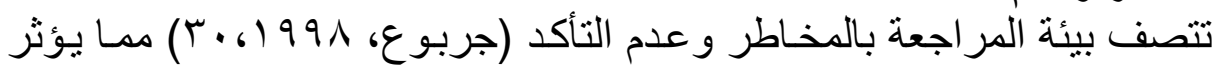

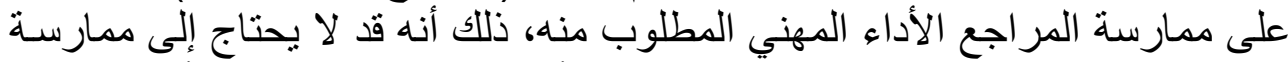

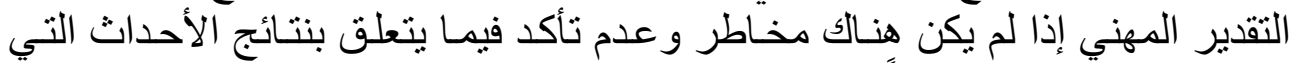

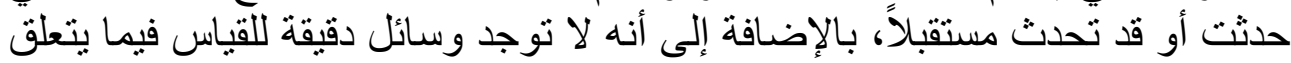

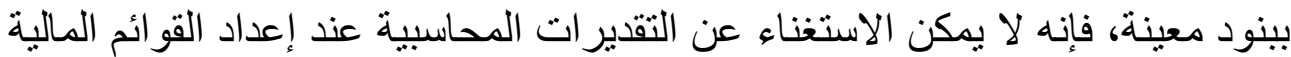

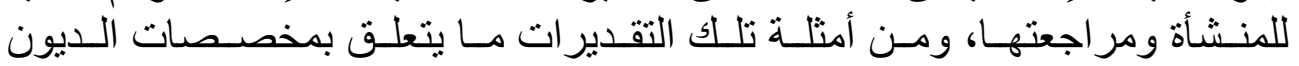

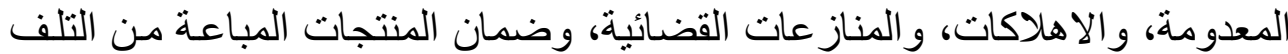

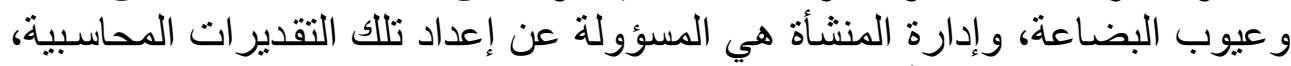

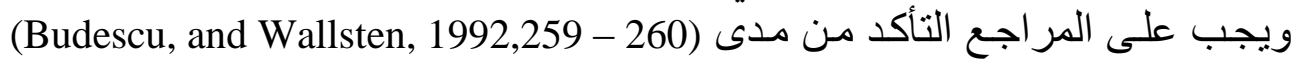
معقوليتها، وملاءمة الافتر اضات التي تعتمد عليها. (Blazek, 1990)

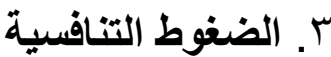

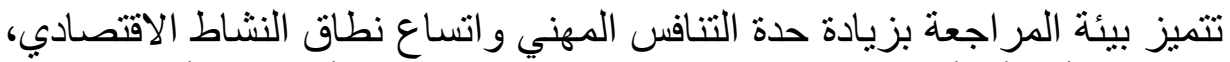

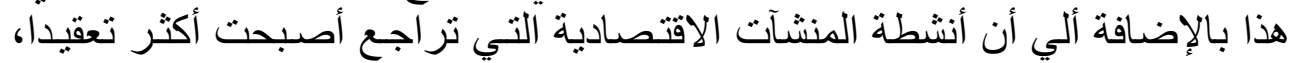

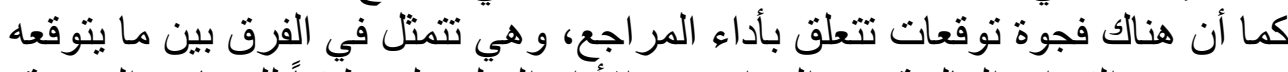

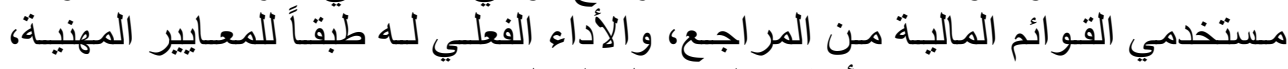
(Godsell, 1991, 22 - 28)

(Guy, and Sullivan, 1988,36-46).

(ICAEW, 1992). 


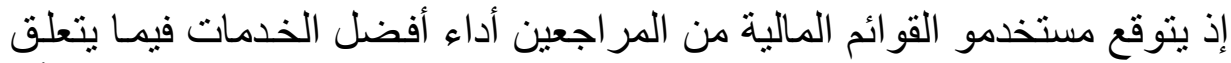

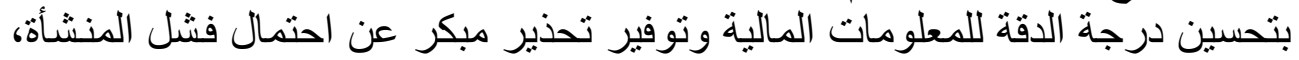

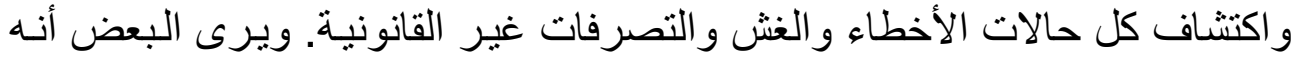

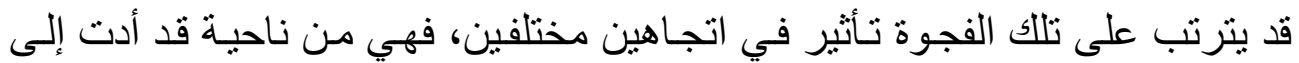

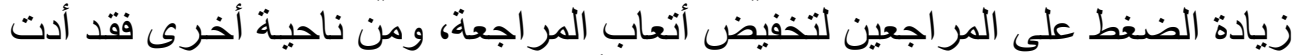

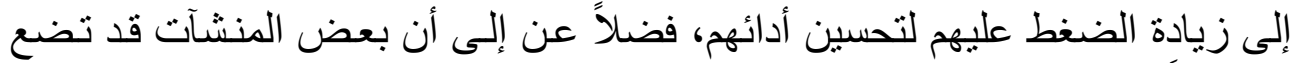

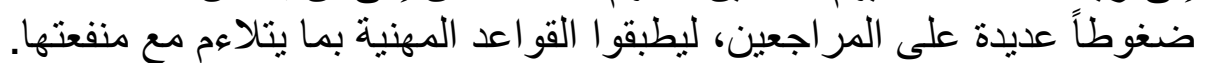

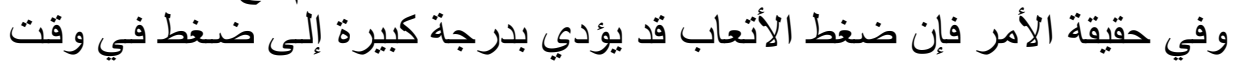

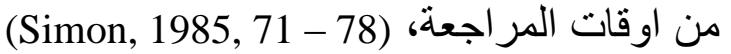

(Elliot, and Kapri, 1979).

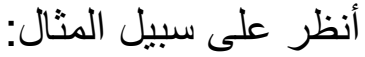

(Firth, 1985, 23-27).

(Simmic, 1980, 161 - 190).

(Taffler, and Ramalingan, 1981).

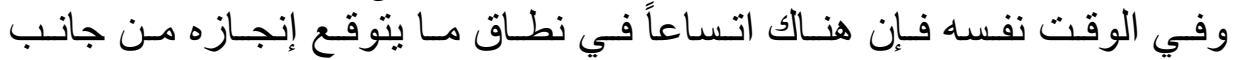

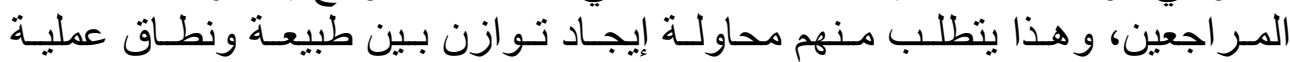

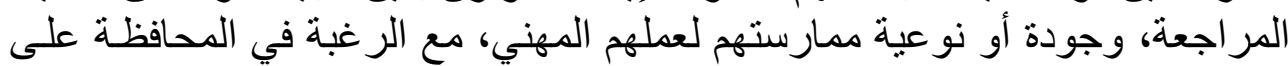
علاقات طيبة مع العملاء. (106) - Journal of Accountancy, 1989,101)

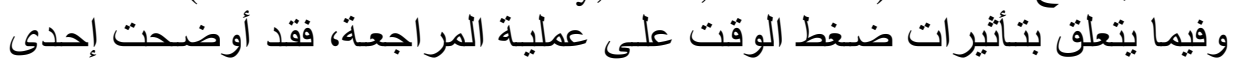

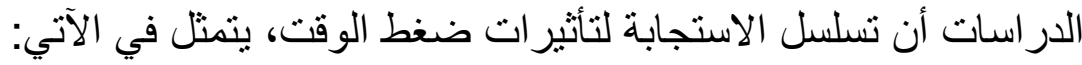
(Mcdaniel, 1990, 267 - 270).

ا . يحاول المر اجعون تسريع أدائهم للأعمـال، بهدف أداء الأعمال نفسها في وقت

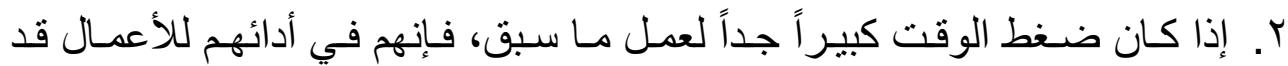

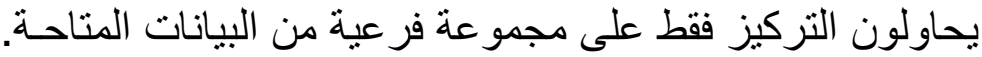

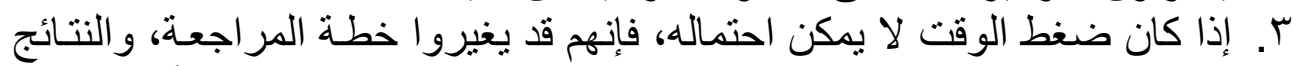

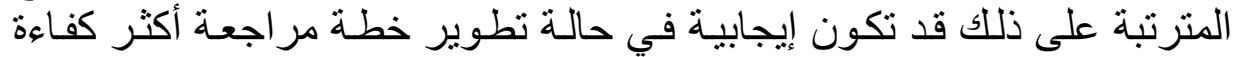

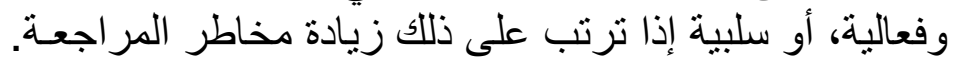

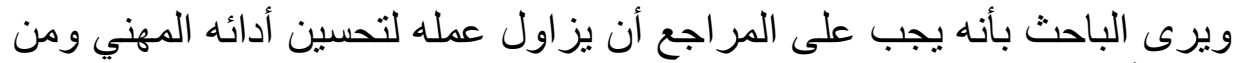

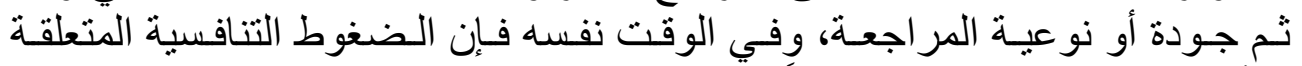

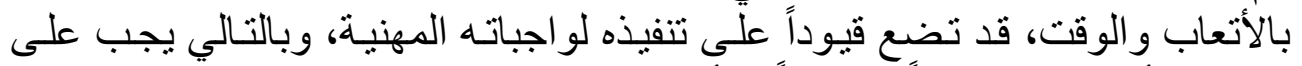

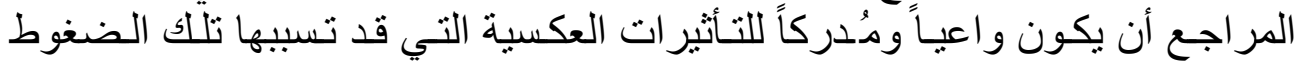
و التحيزات التي قد تنتج عنها، والتي قد تؤدي إلى زيادة مخاطر المراجية التعة 
تكاد ممارسة مهنة مر اجعة الحسابات في فلسطين تكون معدومة فئة في ظل سلطة فئة

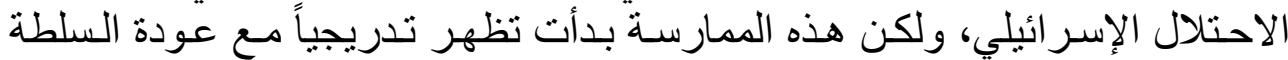

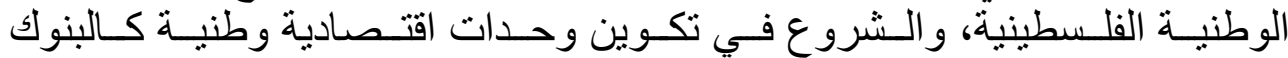

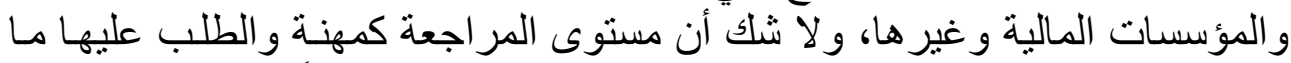

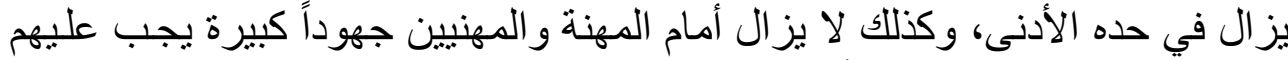

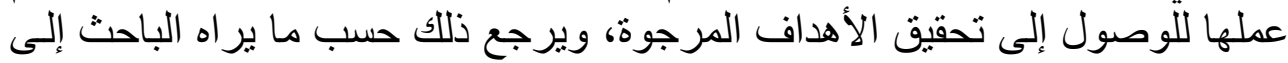

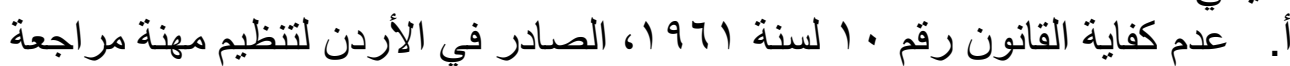

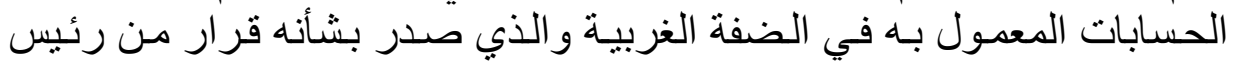
السلطة الوطنية الفلسطينية/ رئيس منظمة التحرير الفلسطينية رقم 0 لسنة السئة

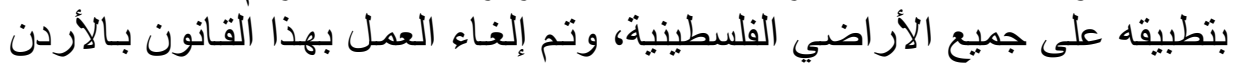

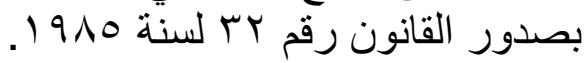
ب. ضـعف إمكانيـات جمعيـة مـدققي الحسـابات، وجمعيـة المحاسـبين و المـر اجعين الفلسطينية القائمة على تنظيم المهنة. ت. انخفاض و عي مستخدمي القوائم المالية بأهمية مر اجعـة الحسابات.

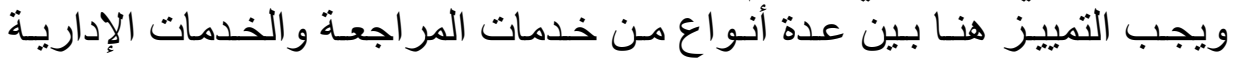
و الاستشارية التي تقدمها عادة شركات ومكاتب مر اجعة التعة الحسابات و والتي تشمل: أ. مر اجعة الحسابات وفقاً لقو اعد ومعايير المر اجعة المعتمدة.

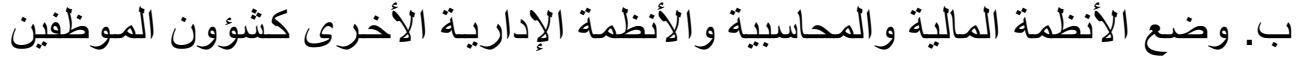
و غير ذلك. ت. تقديم المشورة في الثؤون المحاسبية و المالية بما في ذلك استخدام الحاسب الآلي في تشغيل البيانات المالية. ث. الاستشار ات الضرينية. ج. الاستشار ات في مجال تصميم أنظمة التكاليف. ح. ح. الاستشـار ات الإداريسة. خ. عل عمل الجدوى الاقتصادية للمشاريع الإدية الجديدة.

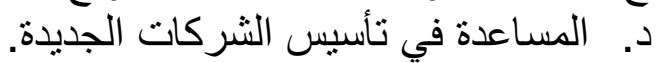
ذذ. التحقيقات الخاصة في الأمور الماليـة.

Y. مكاتب المحاسبة والمراجعة في قطاع غزة المبرة

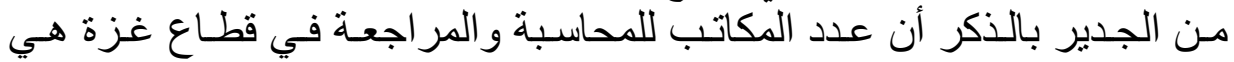

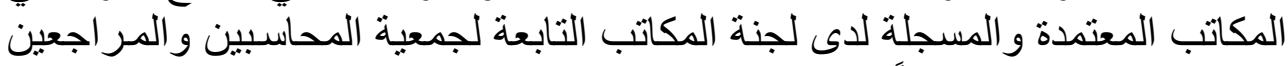
الفلسطينية وهي 10 مكتباً. أما من حيث التوزيع الجغر افي وموقع مكاتب المحاسبة والمر اجعة، فمنطقة غزة المبات

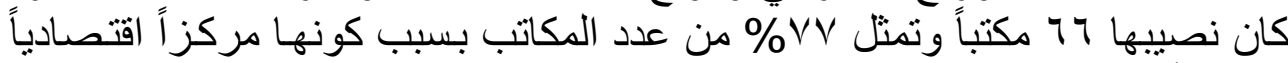
وسياسياً فهي مقر السلطة الوطنية الفلسطينية في الوقت الراهن هند، أما المنطقة الجنوبية 


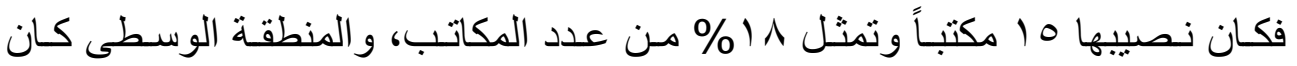

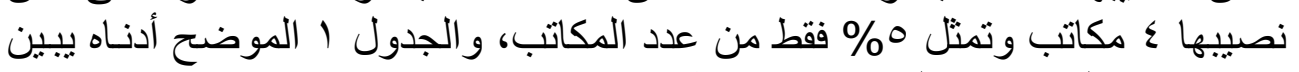

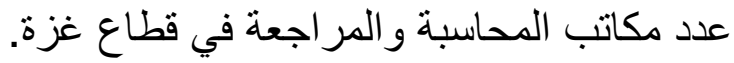

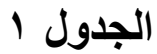

عدد مكاتب المحاسبة والمراجعة في قطاع غزة

\begin{tabular}{|c|c|c|c|}
\hline النسبة المئوية & عدد المكاتب & الإيضاحات & 5 \\
\hline$\% \vee V$ & 77 & منطقة غزة & .1 \\
\hline$\% 1 \wedge$ & 10 & المنطقة الجنوبيـة & $\cdot T$ \\
\hline$\% 0$ & $\varepsilon$ & المنطقة الوسطى &.$r$ \\
\hline$\% 1 .$. & 10 & \multicolumn{2}{|c|}{ المجموع الكلي } \\
\hline
\end{tabular}

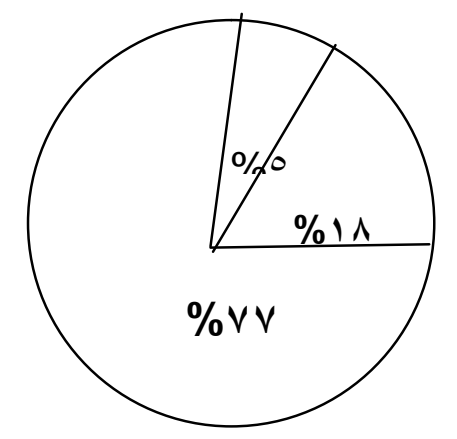

رسم بياني يوضح عدد مكاتب المحاسبة والمراجعة في قطاع غزة حسب النسبة المئوية

r. طبيعة الخدمات التي تقدمها مكاتب المحاسبة والمراجعة:

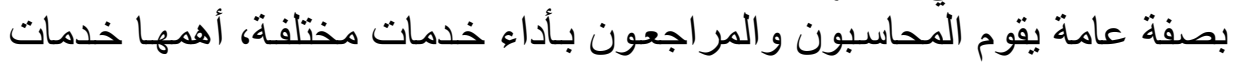
المحاسبة وخدمات المر اجعة، و الخدمات الإدارية والاستشارية الأخرى مثل الخدمات

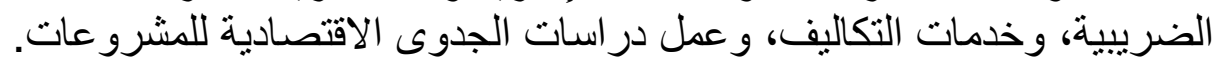

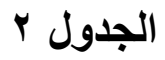

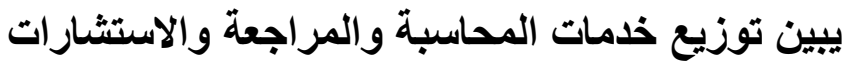

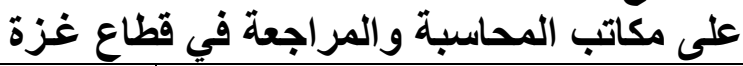

\begin{tabular}{|c|c|c|}
\hline النسبة المئوية & الايضاحات & م \\
\hline$\% \varepsilon$. & خدمات المحاسبة & .1 \\
\hline$\%$ \%. & الخدمات الضريبية & $\cdot r$ \\
\hline$\%$ \%r & خدمات مر اجعة الحسابات &.$\mu$ \\
\hline
\end{tabular}




\begin{tabular}{|c|c|c|}
\hline$\% V$ & خدمات در اسات الجدوى الاقتصادية & $\cdot \varepsilon$ \\
\hline$\% 1 \ldots$ & الكلي & \\
\hline
\end{tabular}

وبالنسبة لخدمات المحاسبة وخدمات المر اجعة فيقوم بها عـادة كل المحاسبين

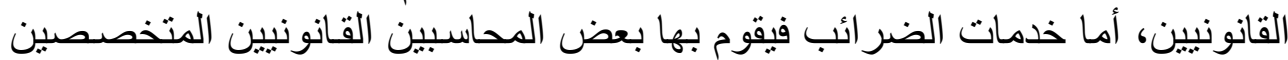

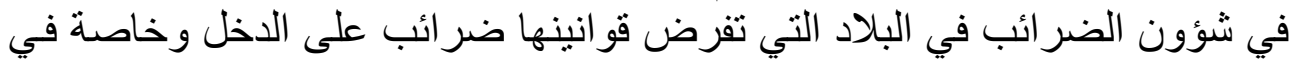

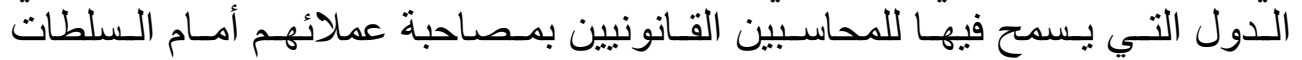

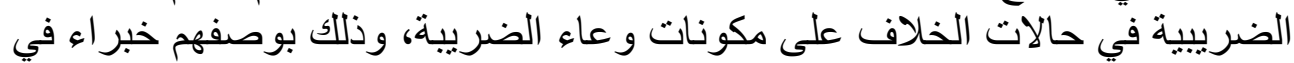

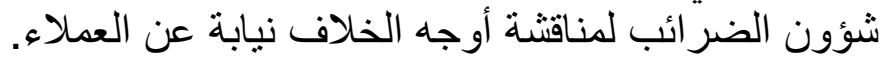

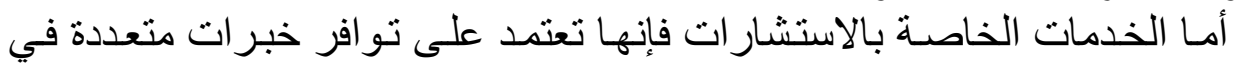

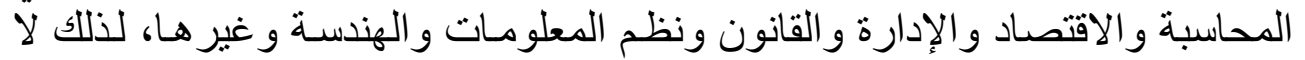

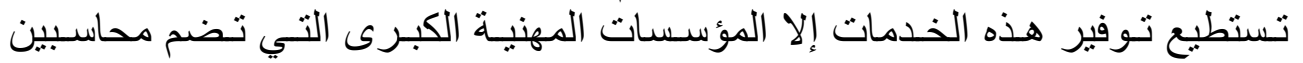
قـانونيين ومستشارين وخبر اء في تلك المجـالات. AICPA, Committee on . Management Services, No. 2 and No.3)

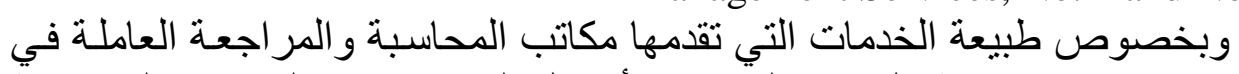

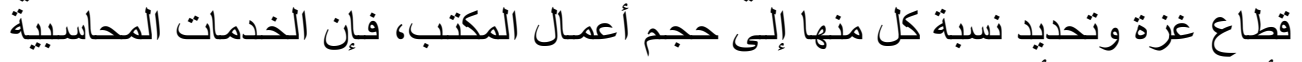

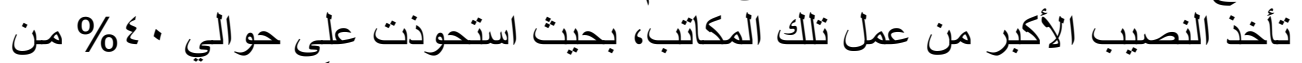

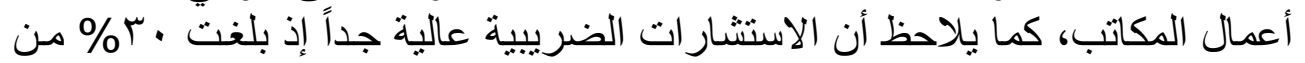

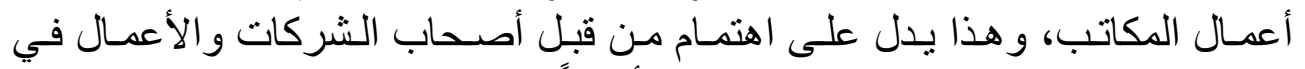

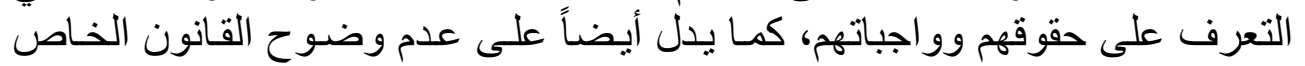

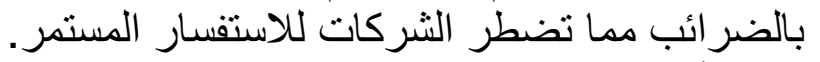

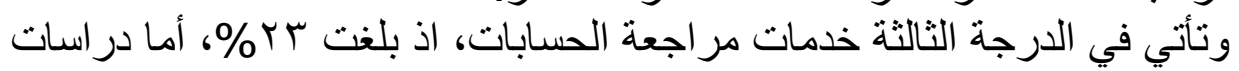

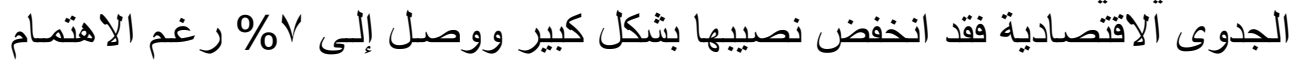

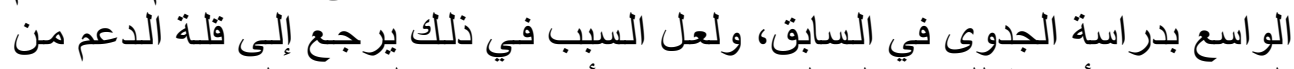

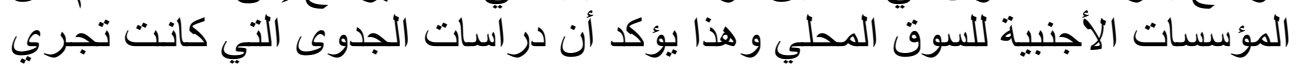
في السابق إنما كانت بهدف التمويل.

\section{محددات البحث}

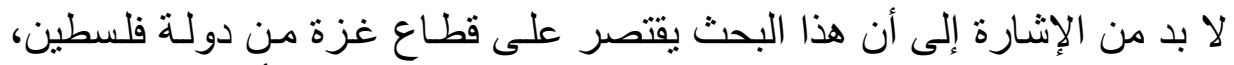

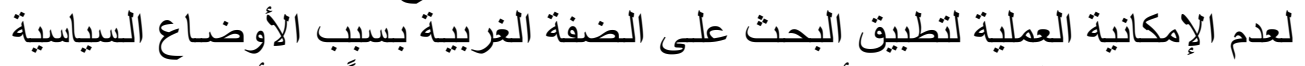

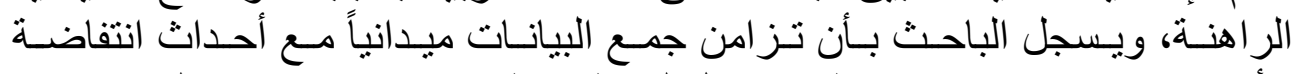

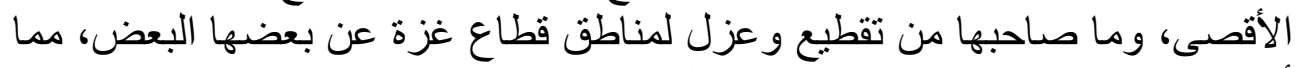

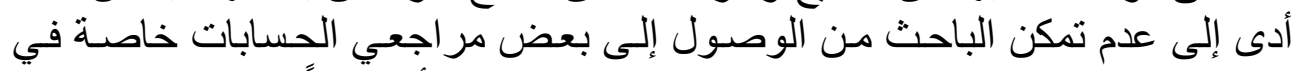

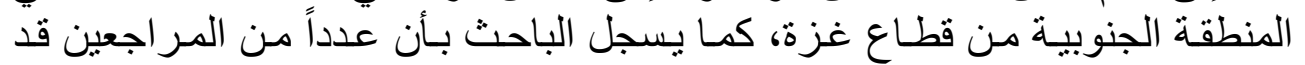
اعتذروا عن تعبئة الاستبيانات لأسباب مختلفة فئة 
تم تصميم الاستبيانات وأرسلت إلى جميع مجتمع الدراسة من مر اجعي اجعي الحسابات

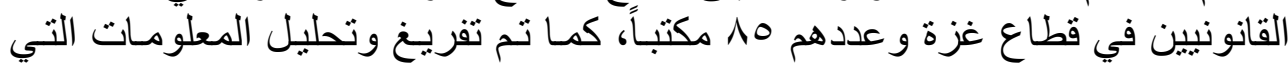

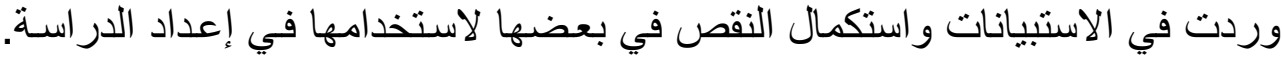

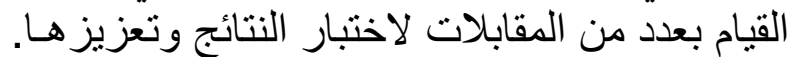

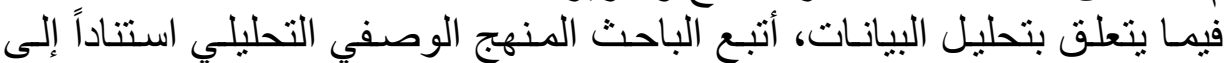

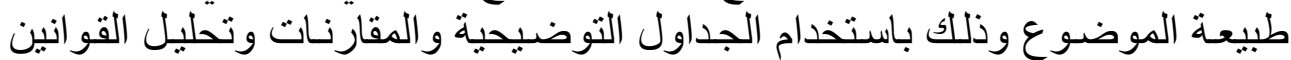

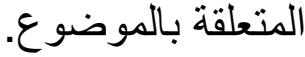

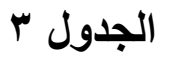

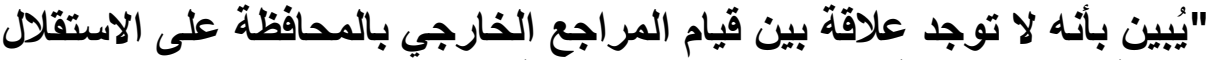

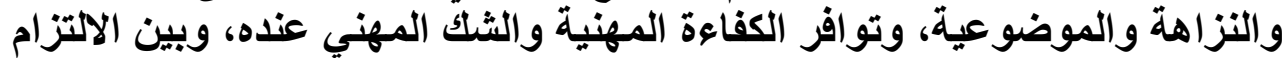
بالأداء المهني السليم"

\begin{tabular}{|c|c|c|c|c|}
\hline Descriptions & Frequency & Percent & Valid Percent & $\begin{array}{c}\text { Cumulative } \\
\text { Percent }\end{array}$ \\
\hline مو افق بشدة Valid & $\varepsilon r$ & $71 . \leqslant T$ & $71 . \leq \pi$ & $71 . \leq r$ \\
\hline مو افق & 19 & TV.IE & TV.IE & ᄉᄉ.OV \\
\hline لا أو افق & 0 & V.1 $\varepsilon$ & $V .1 \leq$ & 90.11 \\
\hline لا أوافق بشدة & $r$ & Y.AT & Y.AT & $91.0 \mathrm{~V}$ \\
\hline محايد & 1 & $1 . \varepsilon r$ & $1 . \leqslant T$ & $1 \ldots$ \\
\hline المجموع & $V \cdot$ & $\cdots \ldots$ & $1 \ldots$ & - \\
\hline
\end{tabular}




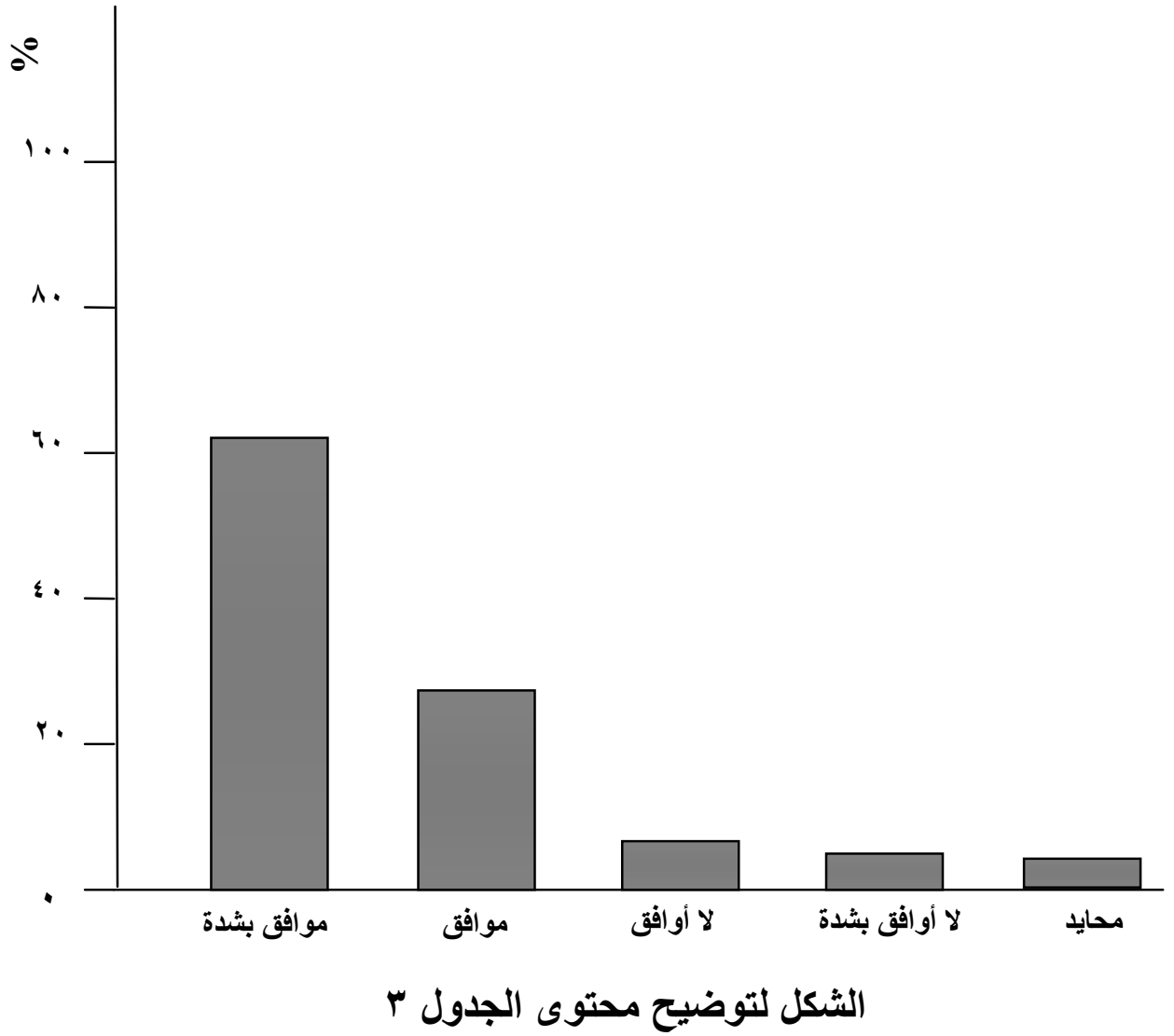

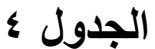

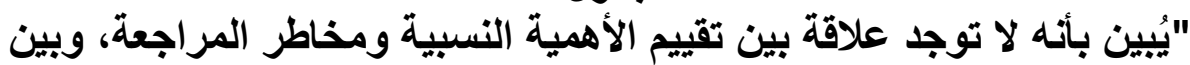

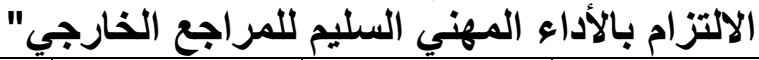

\begin{tabular}{|c|c|c|c|c|}
\hline Descriptions & Frequency & Percent $\%$ & $\begin{array}{c}\text { Valid } \\
\text { Percent }\end{array}$ & $\begin{array}{c}\text { Cumulative } \\
\text { Percent }\end{array}$ \\
\hline مو افق بشدة Valid & $\varepsilon$. & $0 V .1 \leq$ & $0 V .1 \leq$ & $0 V .1 \leq$ \\
\hline مو افق & $r$. & Y^.OV & rA.OV & $10 . V 1$ \\
\hline لا أو افق & $\mu$ & $\varepsilon .1 q$ & $\varepsilon .1 q$ & $9 . \ldots$ \\
\hline لا أو افق بشدة & $r$ & Y.AT & Y.AT & $9 Y . \wedge 7$ \\
\hline محايد & 0 & V.1 1 & $9.1 \leq$ & $1 \ldots$. \\
\hline المجموع & V. & $1 \ldots$. & $1 \ldots$ & - \\
\hline
\end{tabular}




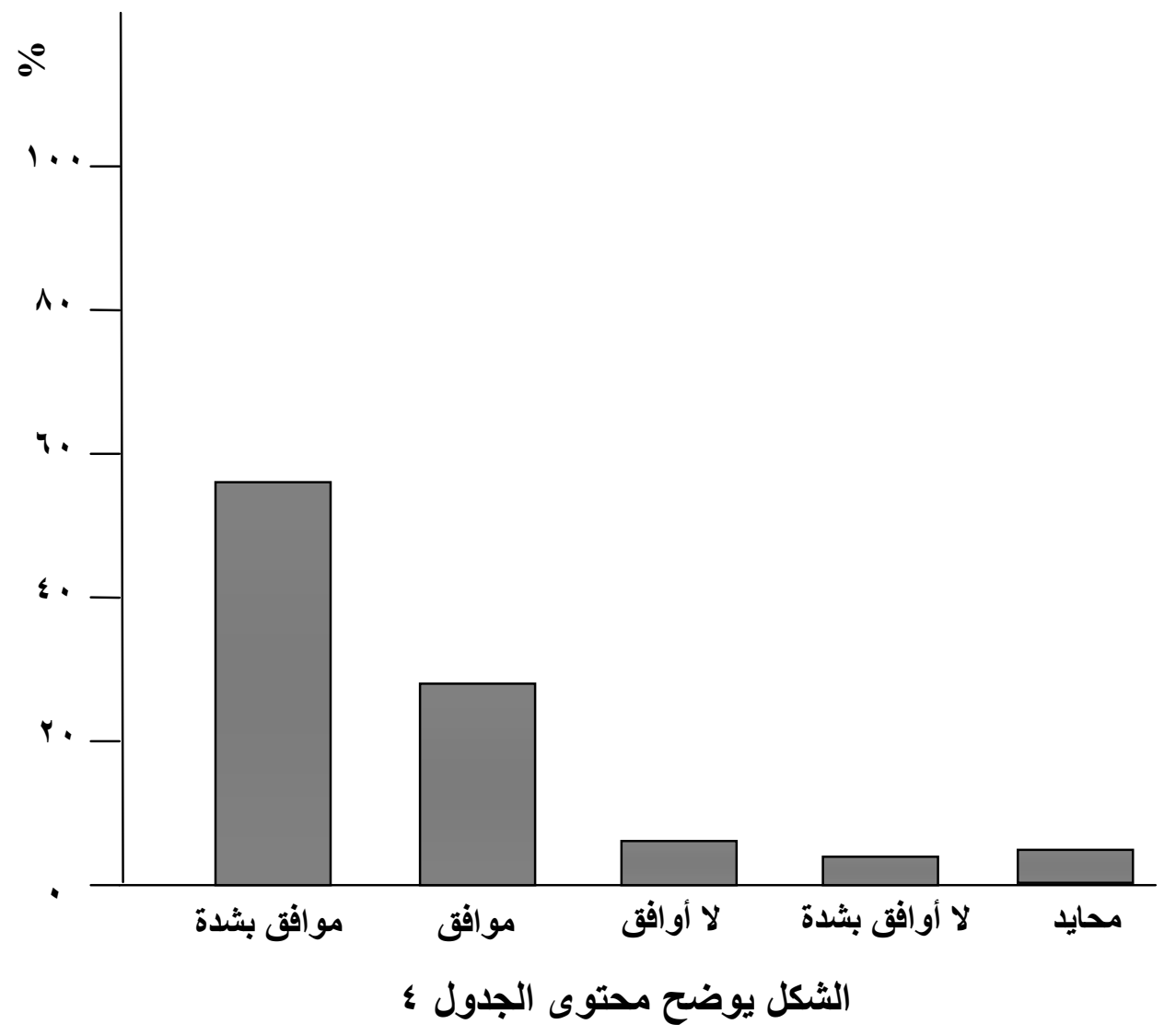

\section{- الجدول}

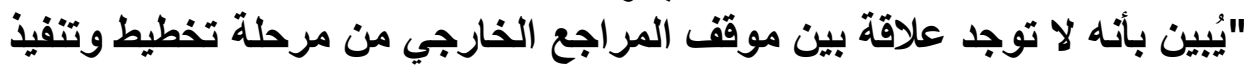

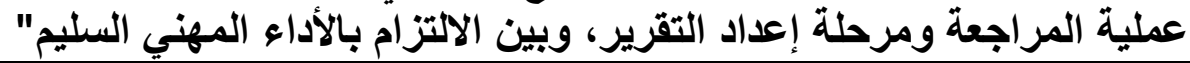

\begin{tabular}{|c|c|c|c|c|}
\hline Descriptions & Frequency & Percent $\%$ & Valid Percent & $\begin{array}{c}\text { Cumulative } \\
\text { Percent }\end{array}$ \\
\hline مو افق بشدة Valid & $r$. & YA.OV & rA.OV & rA.OV \\
\hline مو افق & $\leqslant 0$ & $7 \varepsilon .19$ & $7 \leq .49$ & $9 Y . \wedge 7$ \\
\hline لا أو افق & $r$ & r.10 & Y.Aт & $90 . V Y$ \\
\hline لا أو افق بشدة & $r$ & T.AT & Y.AT & 91.01 \\
\hline محايد & 1 & $1 . \leqslant Y$ & $1 . \leqslant r$ & $1 \cdots \ldots$ \\
\hline المجموع & $V \cdot$ & $1 \ldots$ & $1 \ldots .$. & - \\
\hline
\end{tabular}




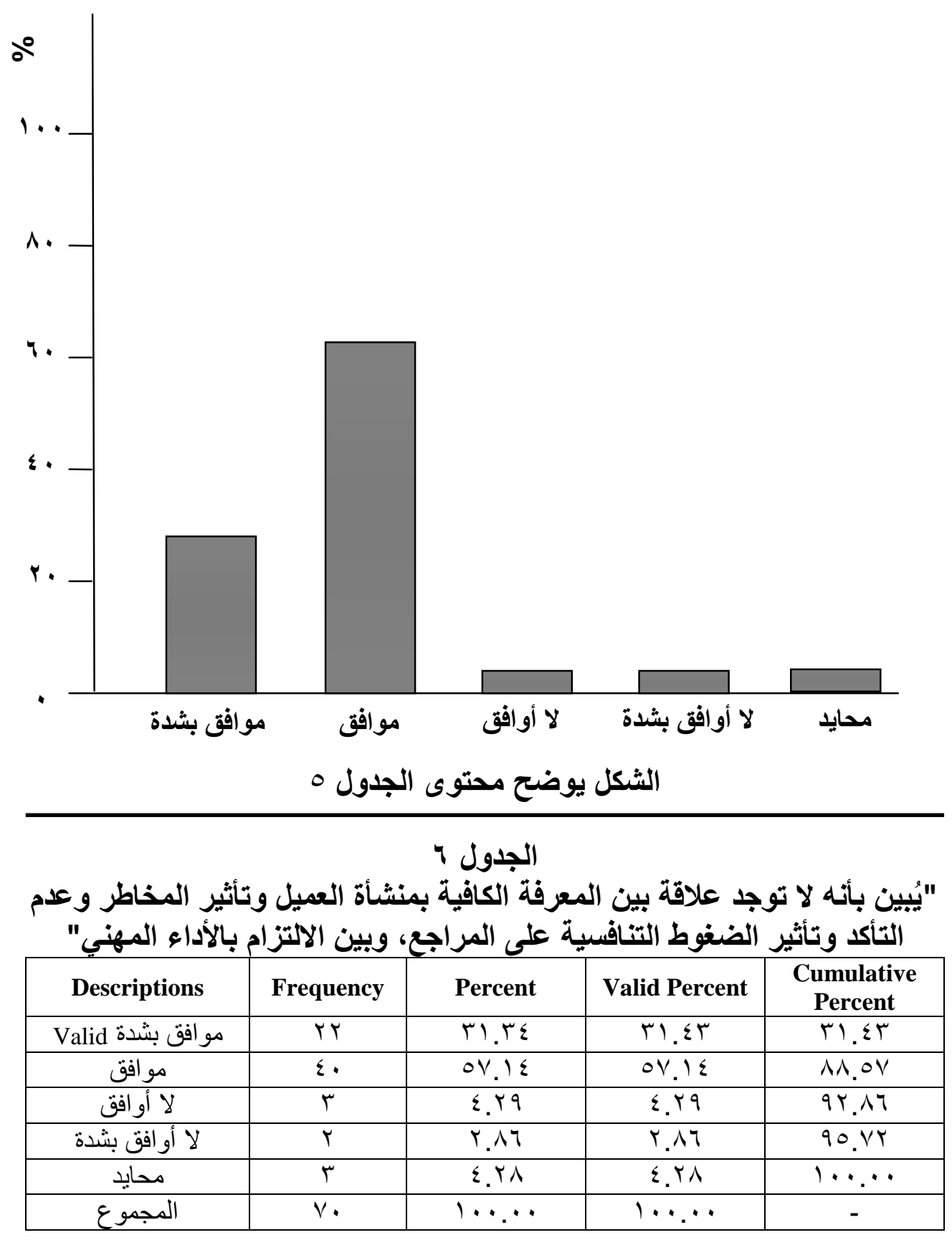




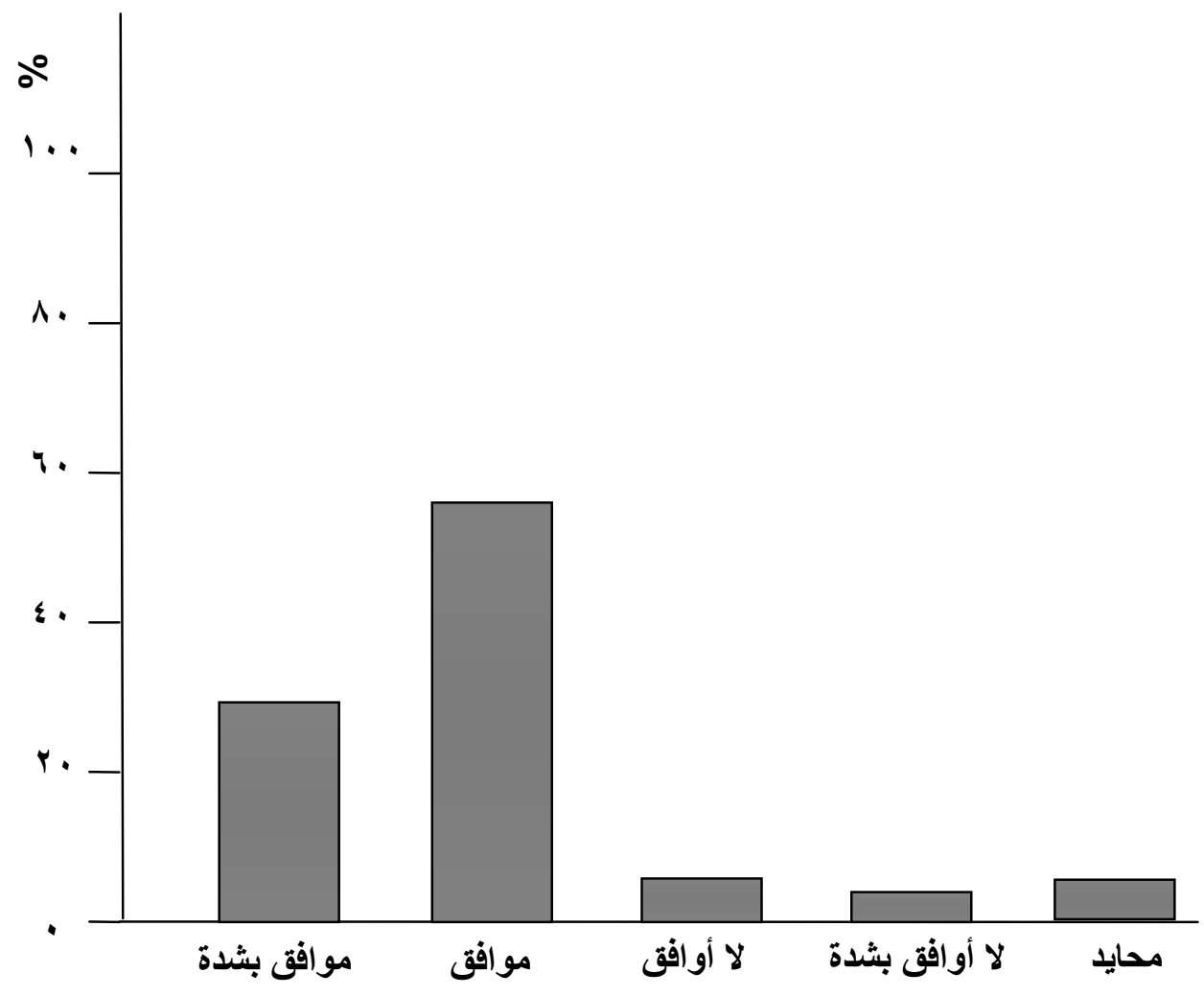

الشكل يوضح محتوى الجدول

لقد تـم إرسـال قو ائم الاستبيانات إلى 10 مكتبـاً في قطاع غزة، وذلك بإتبـاع

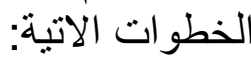

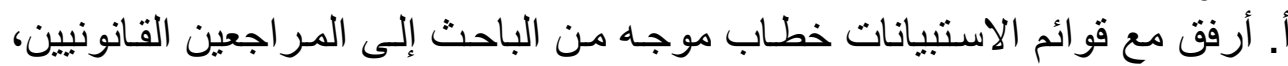

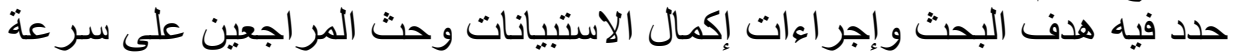
الإجابـة.

ب. أرسلت قوائم الاستبيان إلى جميع الـ 1 م مكتباً وذلك حسب عناوينهم المسجلة في دليل المحاسب الفلسطيني.

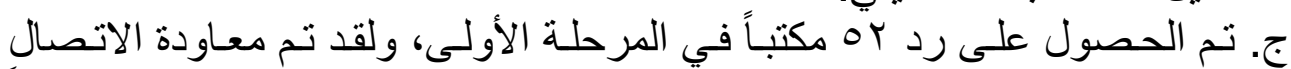

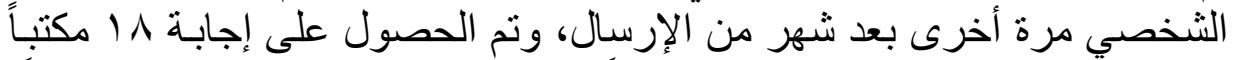

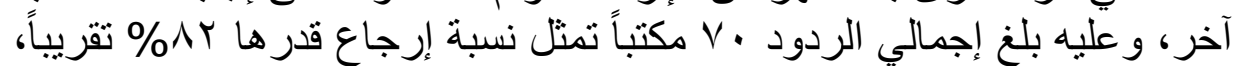
وهي نسبة عالية و معقولة النة 
تحليل نتائج الاراسـة

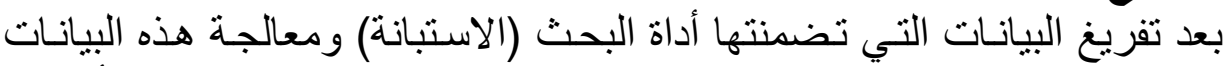

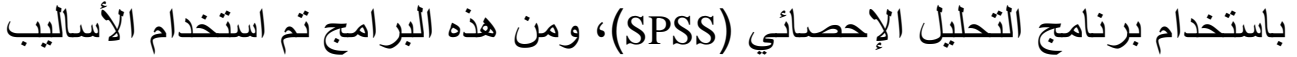
الإحصائية المناسبة للتحقق من صحة الإن فرضيات الدراسة وذللك على النحو الاتي:

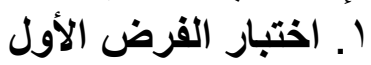

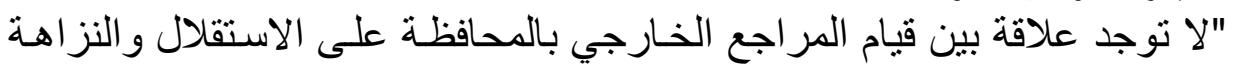

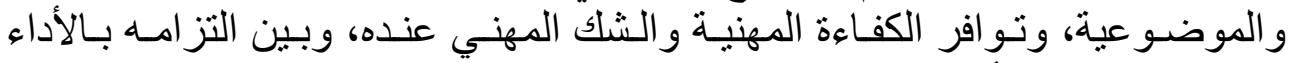

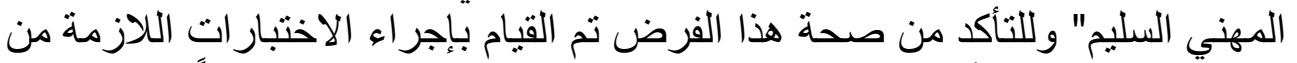

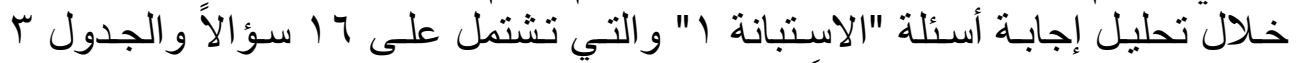

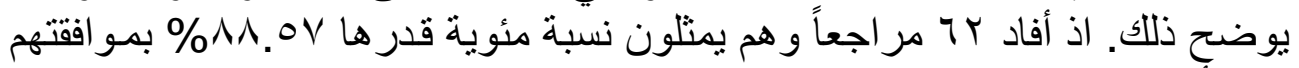

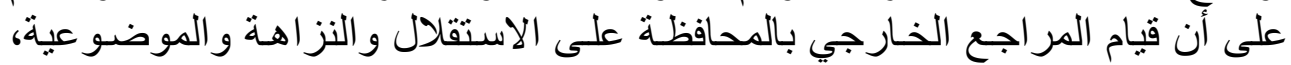

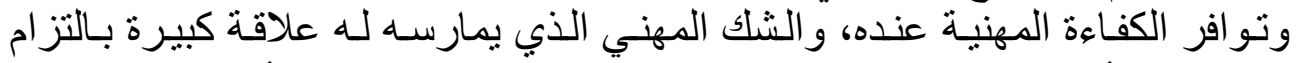
المر اجع بالأداء المهني السليم، و هذا ما يؤيد عدم صحة الفئ الفرضية الأولى.

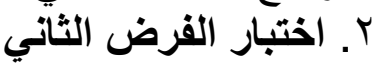

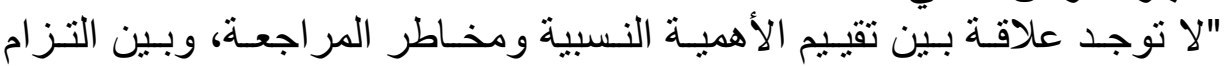

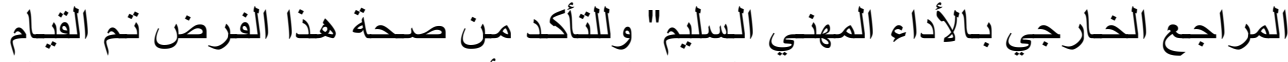

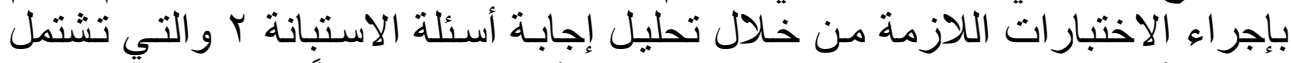

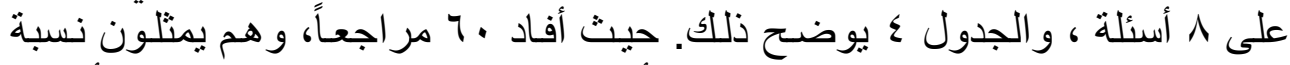

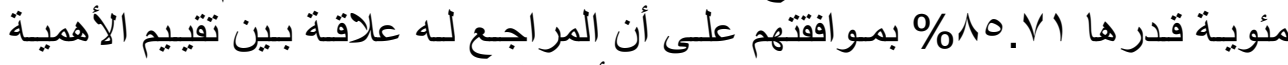

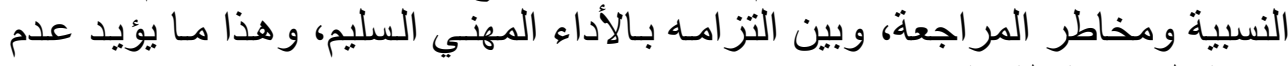

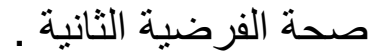

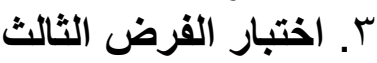

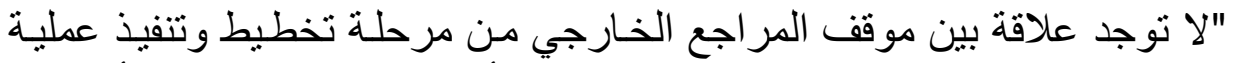

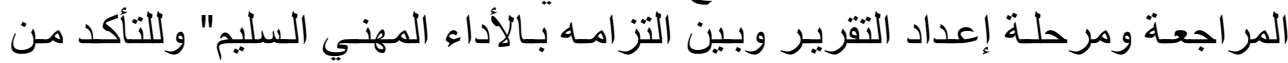

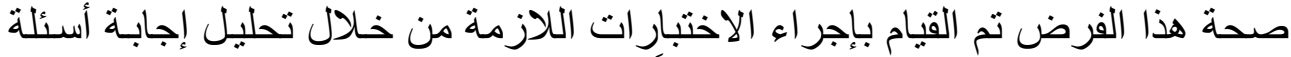

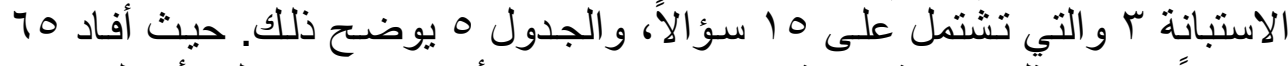

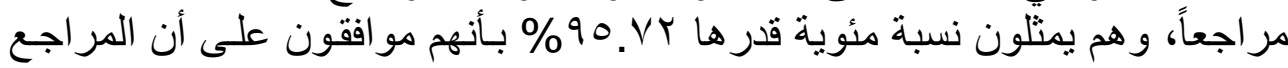

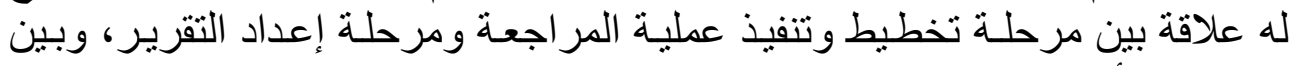

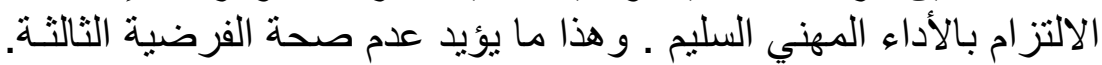

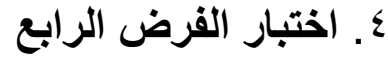

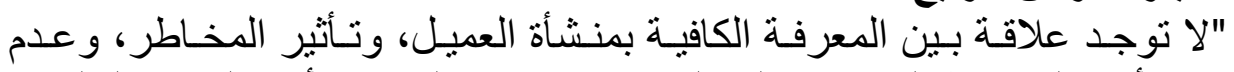

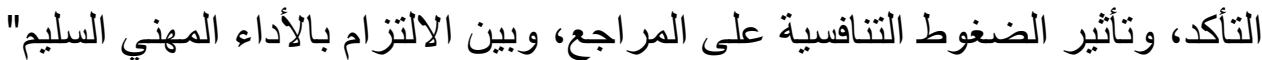

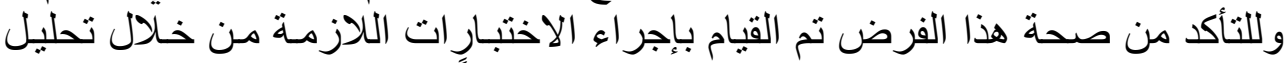

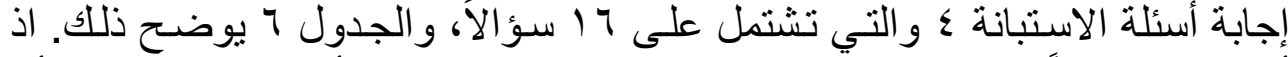

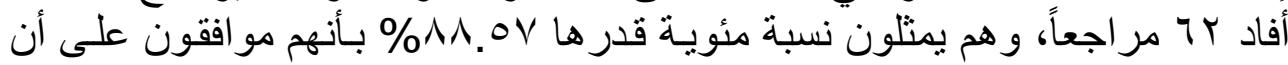

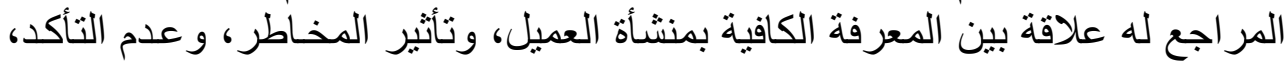


وتأثثير الضغوط التنافسية عليه، وبين الالتز ام بـالأداء المهني السليم، وهذا مـا يؤيد عدم صحة الفرضية الرابعة.

\section{أنتائج والتوصيات} أ. أنتائج

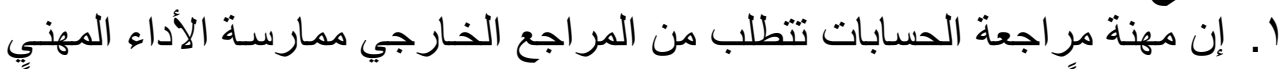

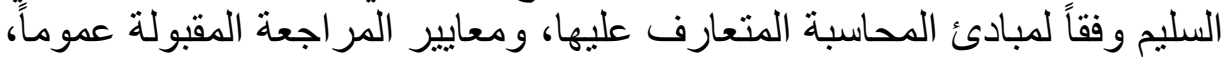
وقو اعد السلوك المهني. r. إن عدم ممارسة الأداء المهني بطريقة فعالة من فئل فيل المر اجعين يعد عاملاً أساسياً

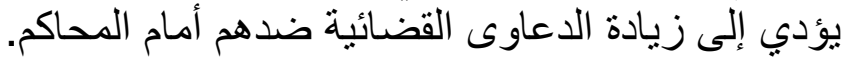

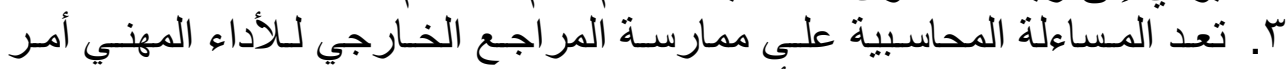

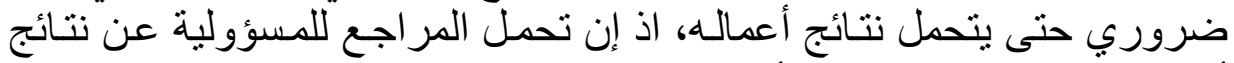

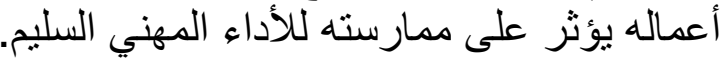

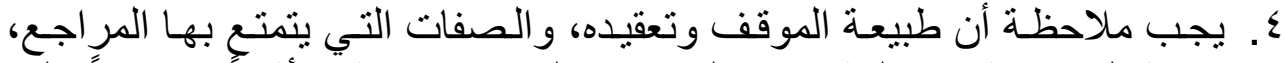

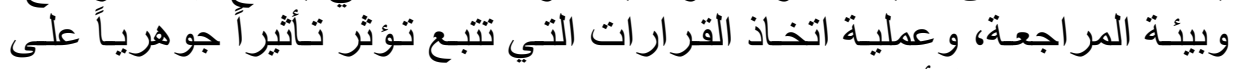
ممارسة المر اجع للأداء المهني عند مر اجعته للقو ائم المالية.

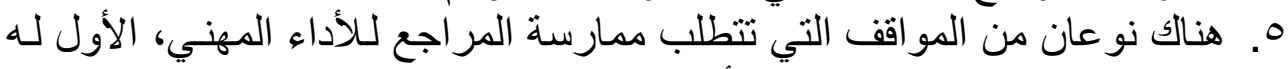

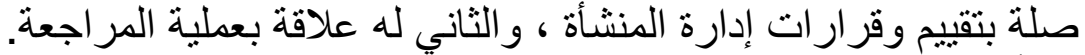

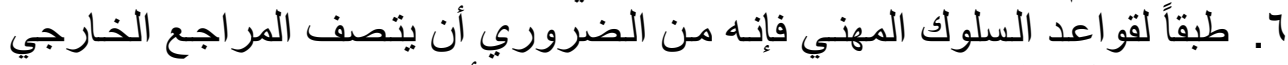

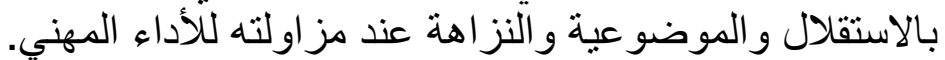

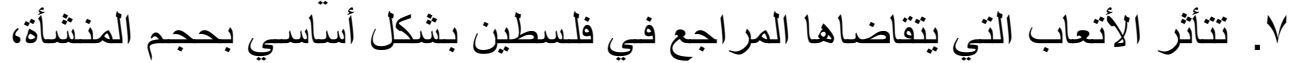

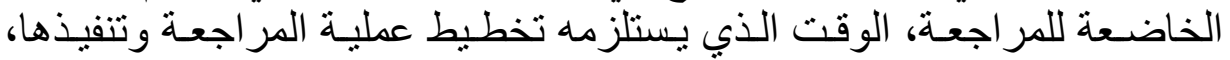

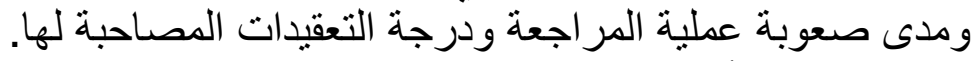

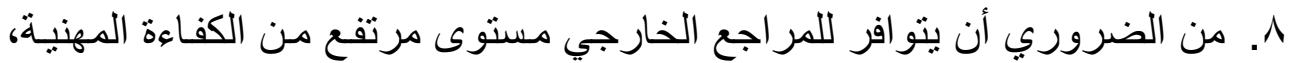

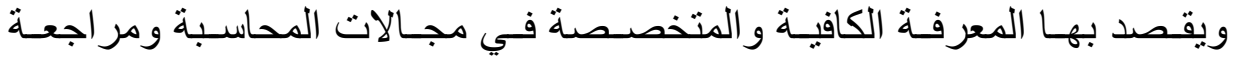

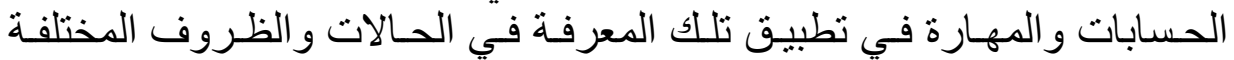
وكذلك السلوك الذي يكتسبه المر اجع من التعليم و التدريب الكافي مثل الاستقلال. ب. التوصيات

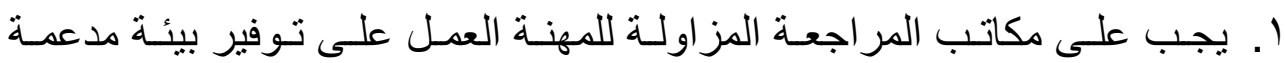

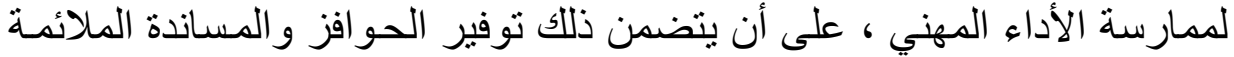

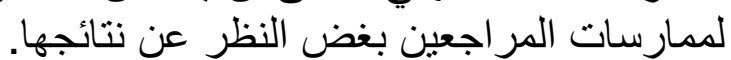

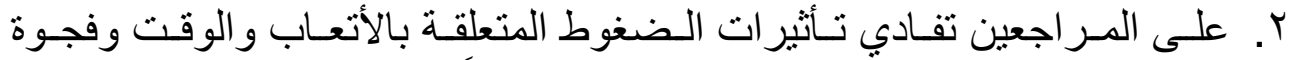

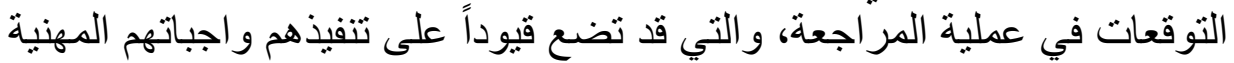

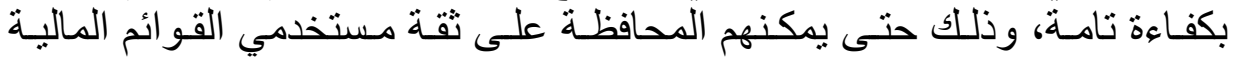

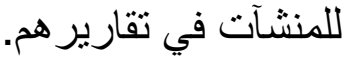

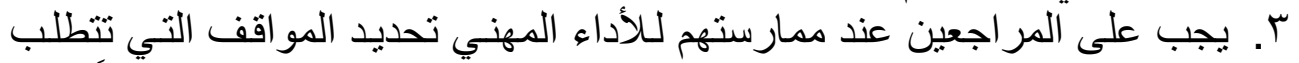
ذللك، والحصول على المعلومـات الملائمسة، وتحديد البدائل تقييمها مبكر اً بقدر البهر 
الإمكان وذلك لتخفيض الضغط والتوتر بسبب الرغبة في مقابلة المو اعبد النهائيـة لاتخاذ القرار ات.

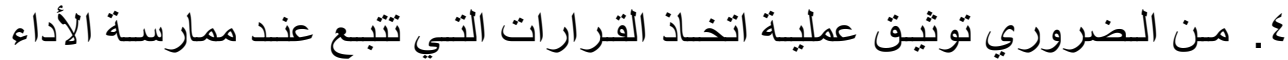

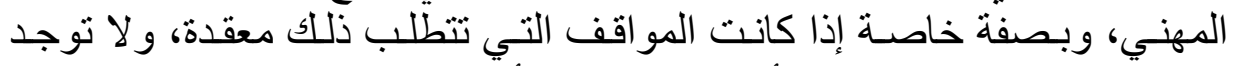

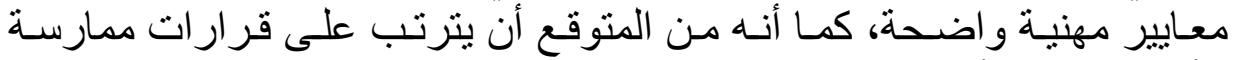
الأداء المهني، تأثثير ات جو هرية على مستخدمي القو ائم المالية.

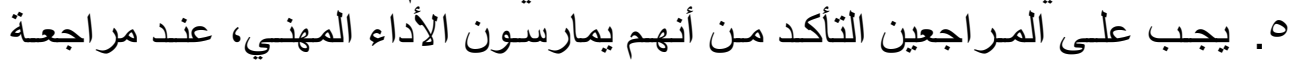

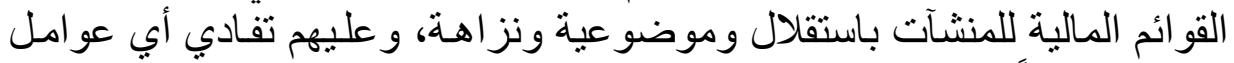

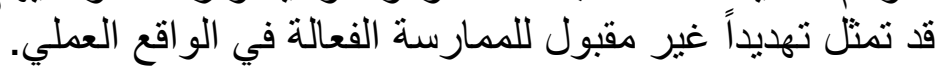

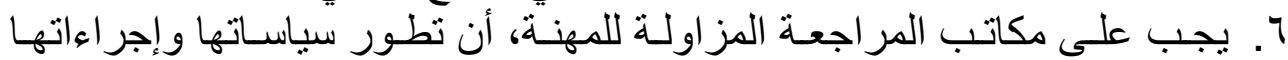

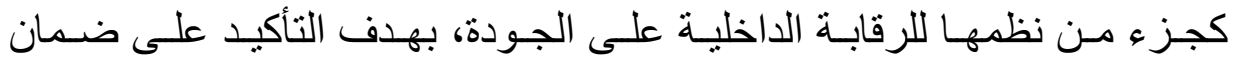

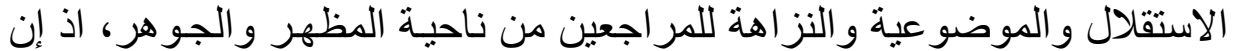

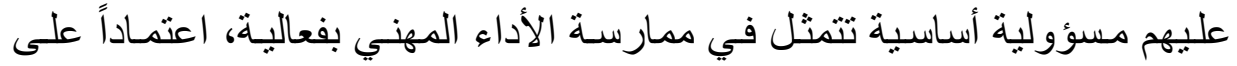
مفاهيم الاستقلال و الموضو عية و النز اهية.

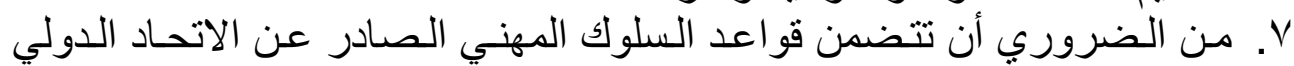

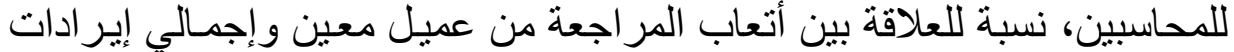

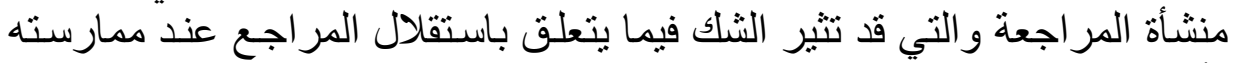

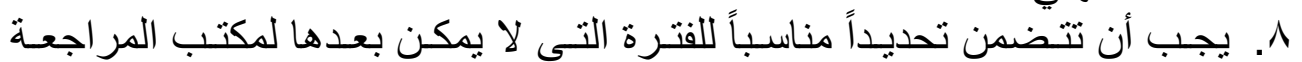

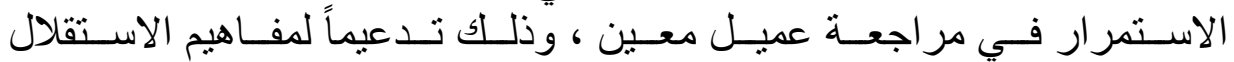

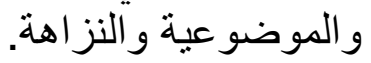

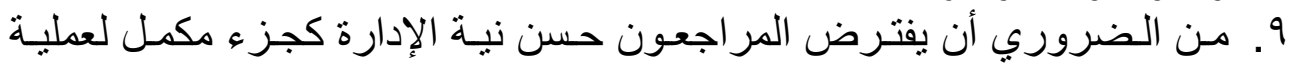

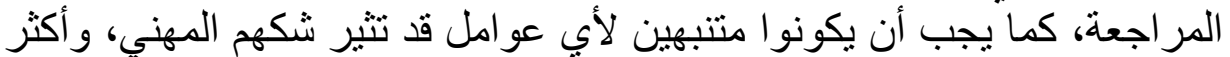

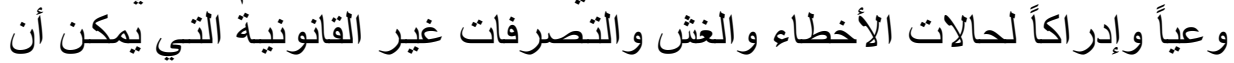
تحدث، والعوامل التـي يجب أن تؤخذ في الاعتبـار عند التيقن من احتمـالات التات حدوثها.

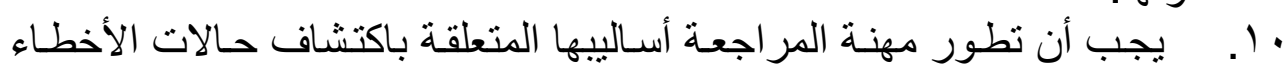

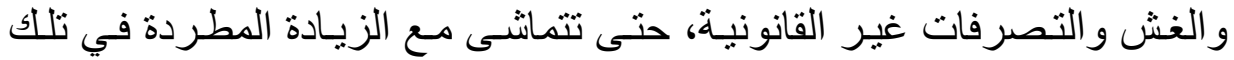

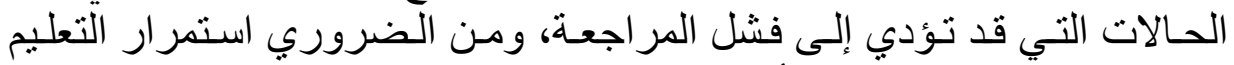

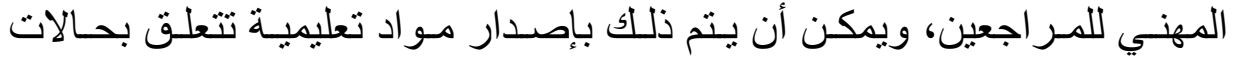

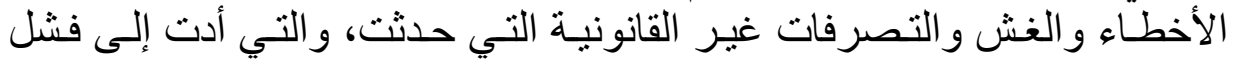
المر اجعة، وقد يؤدي ذلك إلى مساعدة المـر اجعين على تجنب المو اقف الممانلـة وتحسين جودة خدماتهم. 


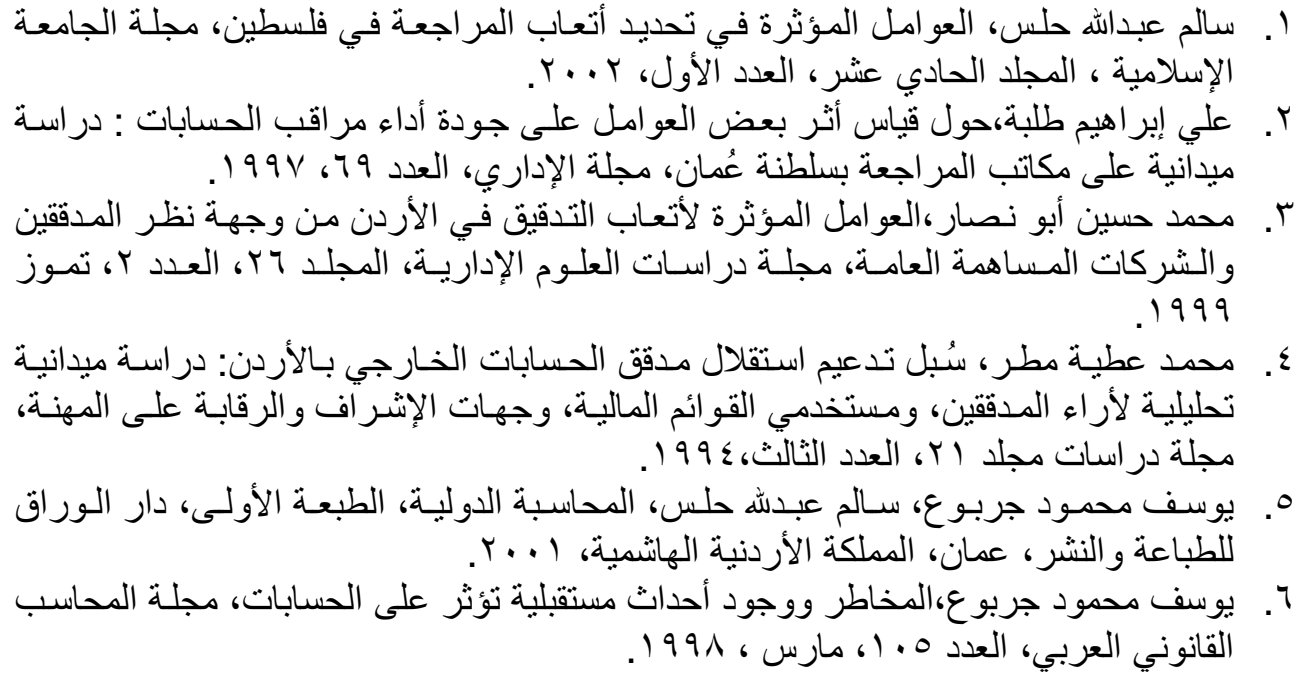

\section{ثانياً. المراجع باللغة الاجنبية}

1. Albrecht, W.S. and Willingham, J.J, An Evaluation of SAS- No.53, the Auditor's Responsibility, to Detect and Report Errors and Irregularities, in the Expectation Gap Standards, American Institute of Certified Public Accountants, 1993.

2. American Insstuitute of Certified Public Accountants, The Report of the Commission to Study the Auditors Responsibilty (Cohen Committee Report),New york: AICPA 1978.

3. American Institute of Certified Public Accountants, Committee On Auditing Procedures, (GAAP), New York, 1984.

4. American Institute of Certified Public Accountants, Committee On Management Services, No.2 and No.3.

5. American Institute of Certified Public Accountants, The Auditor's Responsibility to Detect and Report Errors, Fraud and Illegal Acts, Circular No.53, No.54, 1998.

6. American Institute of Certified Public Accountants, Statement on Auditing Standards No. 57: Auditing Accdounting Estimates, American Institute of Certified Public Accountants, New York, N.Y, 1988.

7. Antle, R., Auditor's Independence Journal of Accounting Research, vol. 22,No.1, (Spring 1987).

8. Arens, A. A. and Loebbeck, J.K., The Studying of Internal Control and Assessment of Control Risk, Auditing: An Integrated Approach, Third Edition,2002.

9. Arens, A.A. and Loebbecke, J.K., Materiality and Risk, Inherent Risk, Control Risk and Detection Risk, Auditing, 1988, Fourth Edition, 1988.

10. Bailey, A. D. and (et.al), The Audit Staff Assignment Problem: A. Comment, The Accounting Review, (July 1974).

11. Blazek, M.M., An Empirical Study of Bayesian Decision Theory and Auditor Judgment Under Uncertainty, Ph.D. Dissertation, Arizona State University, 1990.

12. Boynton, W.C. and Kell, G.K., Planning Audit Program, Modern Auditing, 1996, Sixth Edition.

13. Boynton, W.C. and Kell, W.G., Planning An Audit, Modern Auditing, 1996, Sixth Edition, 1996.

14. Boynton, W.C. and Kell, W.G. Auditor's Responsibility and the Expectation Gap, Modern Auditing, 1996, Sixth Edition, 1996. 
15. Budescu, D.V. and Wallsten, T. S. , Consistency in Interpretation of Probabilistic Phrases, Australian Journal of Management, The University of New South Wales, (Dec. 1992) .

16. Castello,J.L., The Auditor's Responsibilities for Fraud Detection and Disclosure. Do the Auditing Standards Provide a Safe Harbor?, CAP News Letter, (August 1991).

17. Chewning, G. Parry, K. and Wheeler, S., Auditor Reporting Decisions Involving Princeples Changes: Some Evidence on Materiality Thresholds, Journal of Accounting Research, Vol. 19, No. 2, 1981.

18. Chidgey, P. and Mitchell, J., Implementing GAAS 1995\1996: A Practical Guide to Auditing and Reporting, The Institute of Chartered Accountants in England and Wales, 1995, 1995\1996, 1995.

19. Citron, C.B. and Toffler, R.J., Auditors Independence and Going Concern Qualification: An Empirical Analysis, A. Paper Presented to the National Conference of the British Accounting Association, the University of Dundee, Scotland, U.K. (4-6 April 1990).

20. Clarence, W. Houghton, D. and John, A.F., Inherent Risk, Auditing: Journal of Practice and Theory, Vol.10, No.1 (Spring 1991).

21. Cohen, J. and Kida, T., The Impacty of Analytical Review Result's, Internal Control Reliability and Experience on Auditor's use of Analytical Review, Journal of Accounting Research, Vol. 27, No. 2, 1989.

22. Elliot, R.K. and Kopri, A., Factors Affecting Audit Fees, Responsibility Research Study No.3, AICPA, 1979.

23. Fess, P.E. and Warren, C.S., Determining Depreciation Methods, Accounting Principles, 1984, 14 ${ }^{\text {th }}$ Edition, 1984.

24. Firth, M., Perceptions of Auditor Independence and Official Ethical Guidelines, the Accounting Review, (July 1980).

25. Firth, M., An Analysis of Audit Fees and Their Determination, Auditing, Vol.4, No.2, (Spring 1985).

26. Gay, G. Schelluch, P. and Reid, I., Users Perceptions of the Auditing Responsibilities for the Prevention, Detection and Reporting of Fraud, Other Illegal Acts and Errors, Australian Accounting Review, (May 1997).

27. Georgiades, G., Consideration of Internal Control in Planning and Audit, Miller- Audit Procedures, Harcourt Professional Publishing, 2001

28. Gipple, D. and Metacif, R.W., Planning Your Professional Development Program, The Journal of Accountancy, (March 1974)

29. Glover, H.D. and Aono,J.Y., Changing the Model for Preventing and Detection of Fraud, Managerial Auditing journal, Vol.10, No.5, (1995).

30. Godsell,D., Auditor's Legal Liability and the Expectation Gap, Australian Accountant, (Feb. 1991).

31. Goldman, A. and Barlev,B., The Auditors- Firm Conflict of Interests: Its Implications for Independence, The Accounting Review, (October 1974).

32. Grinaker, R.L., The Auditor's Responsibility in Expressing An Opinion, The Journal of Accountancy, 1980

33. Guy, D.M. and Sullivan, J.D., The Expectation Gap and Auditing Standards, Journal of Accountancy, (April 1988).

34. Hartley, R.V. and Ross, T.L., MAS and Audit Independent: An Image Problem, The Journal of Accountancy, (November 1982).

35. Higson, A. and Blake,J., The True and Fair Concept- A Formula for international Disharmony: Some Empirical Evidence, The International Jornal of Accounting, The University of Illinois, Vol.288, No.2, (1993). 
36. Huss, H.F. and Jacobs, F.A. Risk Containment: Exploring Auditor Decisions in the Engagement Process, Auditing: A Journal of Practice and Theory, American Accounting Association, (Fall 1991).

37. Hylas, R.E. and Ashton, R.H. Audit Detection of Financial Statement Errors, The Accounting Review, Vol. 57, No.4, 1982.

38. Institute of Chartered Accountants in England and Wales, the Audit Expectation Gap in the united kingdom, London: ICAEW, 1992.

39. International Accounting Standards, (IAS - 32), Paragraphs (47-55), Uncertainties or Future Events May Affect the Accounts, 1998.

40. Jancura, E.G. and Lilly. F.L., SAS- 3 and the Evaluation of Internal Comtrol System, The Journal of Accountancy, (March 1977).

41. Jarvis,P., Professional Education, London, Groom Helm, 1983.

42. Jennings, M., D.C. and Reckers, P.M.J., A Re- examination of the Concept of Materiality: Views of Auditors, Users and officers of the Court, Auditing: A Journal of Practice and Theory, Vol.6, No.2, 1986-1987.

43. Kieso, D. E. and Weygandt, J.J., Treatment of Changing Accounting Methods of Inventory, intermediate Accounting, 1998, Ninth edition.

44. Krogstad, J.L. Ettenson, R.T. and Shanteau, J. (1984 - 1985) Context and Experience in Auditor's Materiality Judgments Auditing: A Journal of Practice and Theory, Vol.4, No.1 (1984- 1985).

45. Larsen, K.D., Inventory and Cost of Goods Sold, Financial Accounting, 1989, Fourth Edition, 1989.

46. Madision, R.L. and Ross, W.A., The new fraud detective, the national public Accountant, (August 1990), P.41.

47. Matsumura, E.and Trucker,P., Fraud and Error Detection, A Theorietical Foundation, The Accounting Review,1992.

48. Mautz, R.K. Toward a Philosophy of Auditing In: Auditing Looks Ahead Haward Setter (ed.), University of Kansas Printing Service, 1972.

49. Mautz, R.K., Towards a Philosophy of Auditing in: Auditing Looks Ahead, Haward Stettler, (ed.) University of Kansas Printing Services, 1972.

50. Mautz, R.K. and Sharaf, H.A., The Philosophy of Auditing, Sarasota: American Accounting Association, 1961.

51. Mc Daniel, L.S., The Effect of Time Pressure and Audit Program structure on Audit performance, Journal of Accounting Research, the Institute of Professional Accounting: Chicago, (Autumn 1990).

52. Meigs R.F.and W.B., Methods of computing Depreciation, Accounting: The Basic for Business Decision, 1990, Eighth Edition,1990.

53. Meigs, W.B. and Meigs, R.F. The Depreciation of Tangible Assets, Accounting, 1981, Fifth Edition,1981..

54. Mosich, A.N. and Larsen, E.J., Treatment of Changing Accounting Methods of Tangible Assets, Intermediate Accounting, 1986, Sixth Edition.

55. Muller, K. and Shirm, A., Environmental Performance Indicators, Ellipson Ltd., (June 1999).

56. Nichols, D. R. and Smith, D. B., Auditor Gredibility and Auditor Changes, Journal of Accounting Research, Vol. No.2, (Autumn 1983).

57. Nichols, D.R. and Price, K.H., The Auditors-Firm Conflict: An Analysis using Concepts of Exchange Theory, The Accounting Review, (April 1976).

58. Palmrose, Z., Litigation and Independent Auditors, The Role of Business Faiures and Management Fraud, Auditing: A Journal of Practice and Theory, American, Accounting Association, (Spring 1987),1993. 
59. Parker, R.H. and Nobes, C.W., True and Fair: UK AuditorsView, Accounting and Business Research The Institute of chartered Accountants in England and Wiles, Vol.21, No.84, (1991).

60. Read, W.J., Brown, J.E. and Barnett, A.H.,, Changing the way of Auditor's detect fraud, The practical Accountant, (June 1996).

61. Reckers, P.M.J. and Wing, B. , Management's Motive and Its Effect on selected Audit Decisions, Behavioral Research in Accounting, American Accounting Assocication, (Vol.3, 1991).

62. Renshall, J. M., Changing Perceptions Behind The Corporate Report, Accounting Organizations and Society, Vol.2, No. 1, (1976).

63. Robson, D., The Expectation Gap fraud and Error Accounting SA, (November 1988).

64. Shockley, R.A., Perceptions of Auditors Inclependence: An Empirical Analysis, The Accounting Review, (October 1981).

65. Simmic, D., the pricing of services: theory and evidence, the journal of Accounting Research, (Spring 1980).

66. Simmic,D.A., Auditing, Consulting and Auditor Independence, The Journal of Accounting Research VoL. 22, No.2, (Autumn 1984).

67. Simon, D., The Audit Service Market, Audit, Voll. 5, No. 1, (Fall 1985).

68. Simon, D. , the Audit service Market', Auditing, Vol.5, No.1, (Fall 1985).

69. Skerratt, L.L. and Woodhead, A., Modelling Audit Risk', British Accounting Review, The Institute of Chartered Accountants in England and Wales, (June 1992).

70. Smith, J.L. (et-al), Determining Ending Inventory, Accounting Principles, 1986, Second Edition, 1986.

71. Stetter, H.F., Supervision on Audit Staff, Auditing Principles, Fifth Edution, 1982.

72. Taylor, D.H. and Glezen, G.W. The philosophy of Evidence Gathering, Auditing Integrated Concepts and Procedures, 1994, Sixth Edition.

73. The Institute of chartered Accountants in Ireland (ICAI), Report of the commission of Inquiry into the Expectations of Users of Published Financial Statements, (Ryan Commission), Dublin: ICAI, 1992.

74. The Journal of Accountancy, GAO Report Supports Profession's Effort on Audit Quality, the Journal of Accountancy, (May 1989).

75. Toffer, R.J. and Ramalingan,K.S., the Determinats of the Audit Fees in the U.K., city university working papers, 1981,1980.

76. U. S. GOA (The United States General office of Accounting), Report to the Chairman on Banking, Finance and Urban Affairs House of Representatives, Washington: D.C.: U.S. GOA, 1989.

77. U. S. Senate, Subcommittee on Reports, Accounting and Management of the Committee on Government Operations, Metcalf Staff Report, The Accounting Establishment: A Staff Study, U.S. Government Printing Office, 1976.

78. Wallace, W.A., Auditing Complex Accounting Estimates, In The Expectation GAP Standards, American Institute of Certified Public Accountants, 1993.

79. Waller, D., Time to Get Ride of True and Fair The Accountant's Magazine, December 1990.

80. Waller, D., Time To Get Ride of True and Fair? The Accounting, Magazine, (December 1990).

81. William, F. Messier J.R. and Elayzebth, A.A., Inherent Risk and Control Risk Assessment: Evidence on the Effect of Persuasive and Specific Risk Factors, Auditing: A Journal of Practice and Theory, Vol. 19, No.2 (Fall- 2000).

82. Woolf, E., Auditing To Day, Englewood Cliffs, N.J, Prentice- Hall International, Third Edition, 1986. 


\title{
The Factors Affecting The Professional Performance Of The External Auditors In Gaza - Zone From Palestine State
}

\begin{abstract}
The confidence of the external auditor's opinion on the published financial statements is depending on his professional performance, independence and neutrality in practicing his professional duties. So, it is necessary from others to provide the auditor their confidence on his opinion to be attributed with integrity and objectivity, to execute his obligations with highest sense of professional efficiency, depending on his knowledge, skill and experience. The auditor must exercise the professional suspicious in cases of errors, fraud and illegal acts which may be happened.

As the importance of auditing profession is closely connected with the types of services provided to clients and all the beneficiaries of auditing services, so the auditor must comply with quality and the best performance required during the execution of audit work.

The researcher perceives that the auditor must bring to audit process technical competence, integrity, objectivity and independence, to detect material errors which affect the financial position, income statement and to prevent the issue of misleading financial statements in order to earn the public confidence and increase the respect of the financial community for auditing profession.
\end{abstract}

